\title{
Identity Formation of Adolescents who are Homeschooled: Mothers' Perceptions
}

\author{
Peggy Joan McQueen \\ West Virginia University, pbennet1@mix.wvu.edu
}

Follow this and additional works at: https://researchrepository.wvu.edu/etd

Part of the Curriculum and Social Inquiry Commons, Educational Assessment, Evaluation, and Research Commons, Educational Methods Commons, Educational Psychology Commons, and the Social and Philosophical Foundations of Education Commons

\section{Recommended Citation}

McQueen, Peggy Joan, "Identity Formation of Adolescents who are Homeschooled: Mothers' Perceptions" (2019). Graduate Theses, Dissertations, and Problem Reports. 7453.

https://researchrepository.wvu.edu/etd/7453

This Dissertation is protected by copyright and/or related rights. It has been brought to you by the The Research Repository @ WVU with permission from the rights-holder(s). You are free to use this Dissertation in any way that is permitted by the copyright and related rights legislation that applies to your use. For other uses you must obtain permission from the rights-holder(s) directly, unless additional rights are indicated by a Creative Commons license in the record and/ or on the work itself. This Dissertation has been accepted for inclusion in WVU Graduate Theses, Dissertations, and Problem Reports collection by an authorized administrator of The Research Repository @ WVU.

For more information, please contact researchrepository@mail.wvu.edu. 
Identity Formation of Adolescents who are Homeschooled: Mothers' Perceptions

Peggy Joan McQueen

Dissertation submitted

to the College of Education and Human Services

at West Virginia University

in partial fulfillment of the requirements for the degree of

Doctor of Education

in Educational Psychology

Jessica Troilo, Ph.D., Chair

Reagan Curtis, Ph.D.

Amy Root, Ph.D.

Patricia Coon, Ed.D.

Department of Learning Sciences and Human Development

Morgantown, West Virginia University

2019

Key words: Adolescent development, psychosocial theory, identity formation, homeschooling Copyright 2019 Peggy Joan McQueen 


\section{Abstract \\ Identity Development in Adolescents who are Homeschooled: Mothers' Perceptions Peggy McQueen}

Homeschooling is a growing educational choice with very little research about the psychosocial outcomes associated with the process. This qualitative study sought to examine the potential facilitative benefit of homeschooling upon the formation of identity. The participants were 26 parents of homeschooled adolescents in Pennsylvania. Parent responses were examined using thematic analysis. Constituent aspects of parental motivation and methodology were investigated to assess the presence of elements facilitative in the process of identity formation as identified by Erik Erikson $(1959,1963)$. In examining methods used in homeschooling, it was found that the parents in this study are providing the support and encouragement necessary for the exploration that is a critical basis for identity formation. Further, the parents articulated the desire for their adolescent children to explore ideas and activities of personal interest and provided opportunities for them to do so. Implications of these findings are discussed. 


\section{Acknowledgements}

"Gratitude makes sense of your past, brings peace for today, and creates a vision for tomorrow."

With sincere gratitude I would first like to thank Dr. Jessica Troilo for her willingness to take on a student with whom she had not previously worked. Her patience, support, insight, and suggestions were invaluable. When in a quandary regarding data collection and analysis, Dr. Troilo helped as I struggled to process and make meaningful the unexpected events. I would also like to thank all the other committee members, who have each contributed valuable insight and questions.

My amazing mom deserves more thanks than I could ever give. She had long known how important the completion of this degree was to me and was always a stalwart source of encouragement. In her true-to-form selfless nature, she said, "Promise me that you will finish." The significance of her statement lay in the fact that her words were spoken just three days before she joined the angels.

Several dear friends have provided encouragement at just the right time. Many thanks are due to the West family, each of whom contributed in unique and significant ways. Their support and friendship will be cherished forever. I will never have the words to adequately thank Liz for being such a steadfast friend. She and Louise were amazing cheerleaders! I am grateful beyond words for the many times they had just the right thing to say.

My best friend and husband Todd has been unwavering in love, support, encouragement, and has listened for endless hours when I needed a "sounding board." I am forever blessed and grateful. 


\section{Table of Contents}

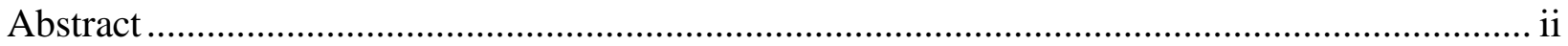

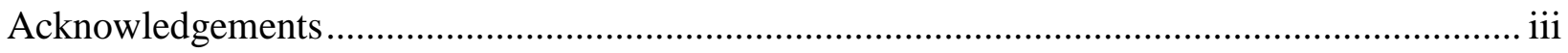

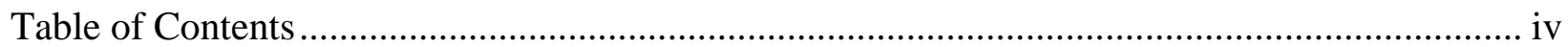

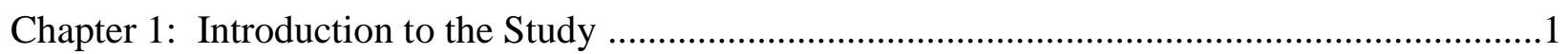

Overview: Adolescence and Identity Formation …...........................................................

Statement of the Problem................................................................................................

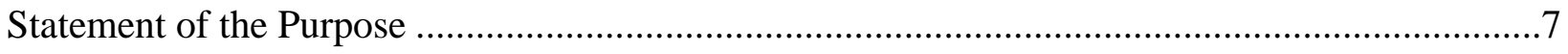

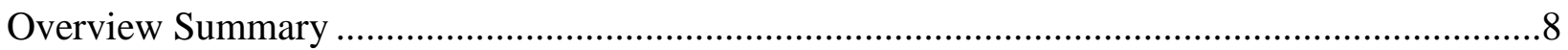

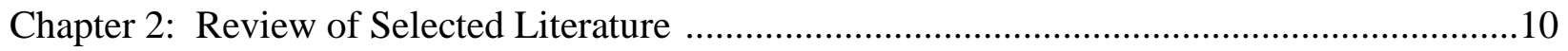

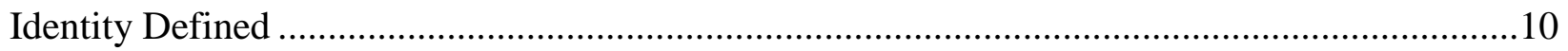

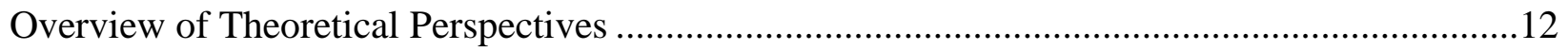

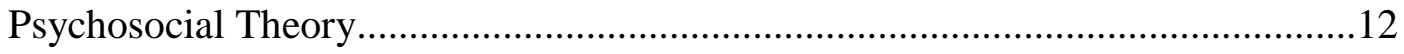

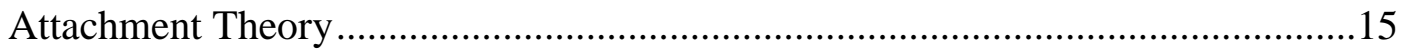

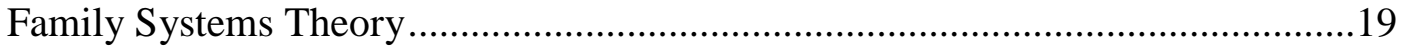

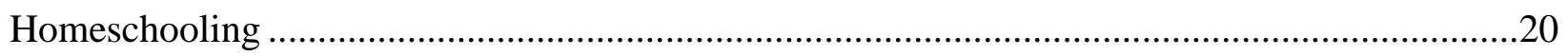

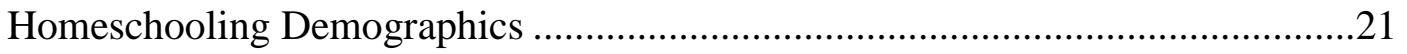

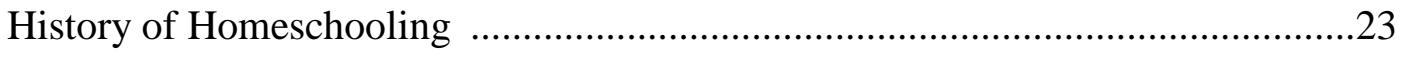

Parental Motivation ..................................................................................26

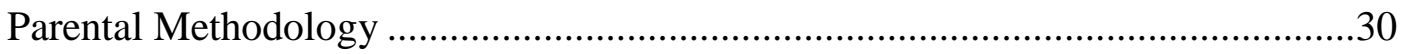

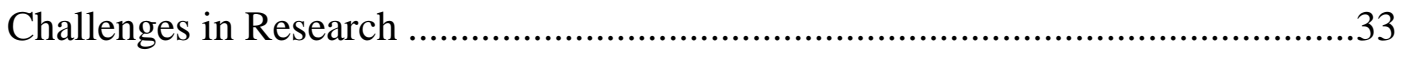

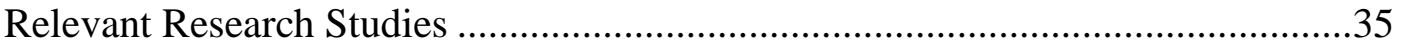

Extrapolations From Theoretical Constructs Applicable to Homeschooling ..........37 


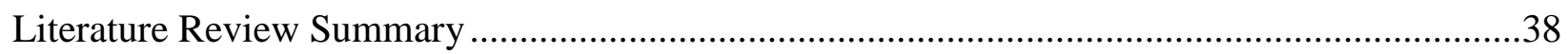

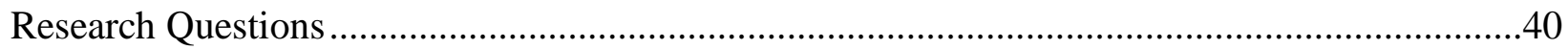

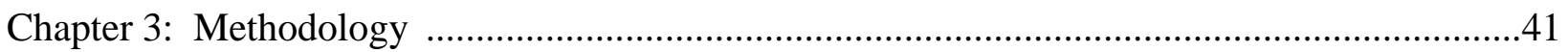

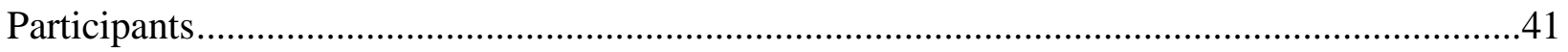

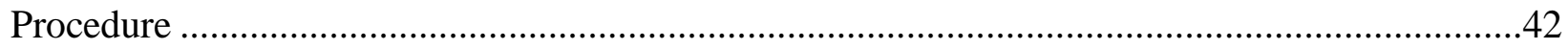

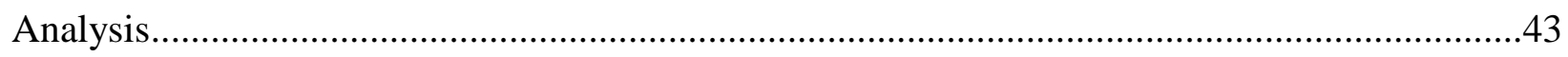

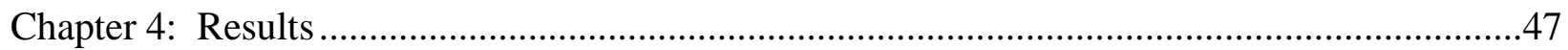

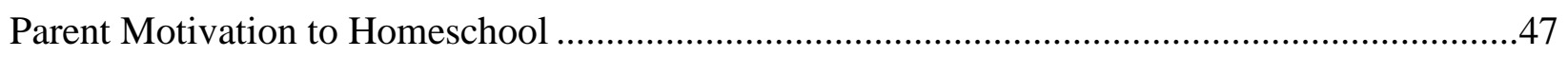

Motivation related to Academic Concerns ..............................................................47

Motivation related to Environmental Concerns ...................................................50

Motivation related to Moral and/or Religious Concerns..........................................51

Reactive Motivational Factors...............................................................................53

Homeschooling Methods and Adolescent Identity Formation ....................................................54

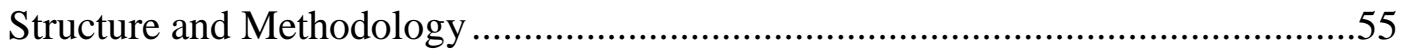

Individualization, Experiential Learning, and Maturation ......................................56

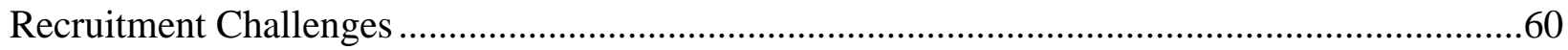

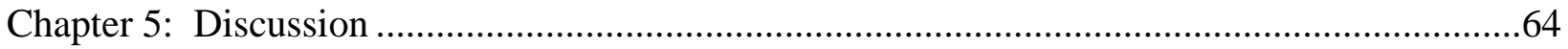

Mothers' Motivation to Homeschool and Adolescent Identity Formation .......................................65

Homeschooling Methods and Adolescent Identity Formation .......................................................68

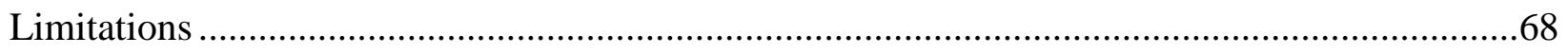

Sampling Methodology …………………………….......................................69

Parental Education Levels ...........................................................................69

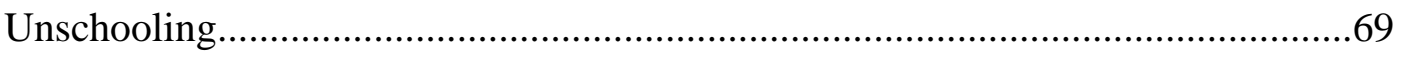




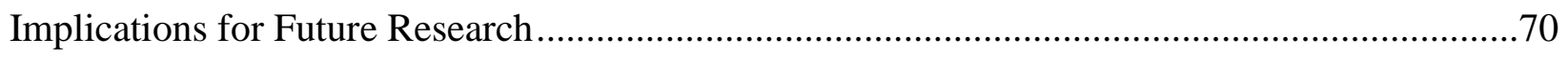

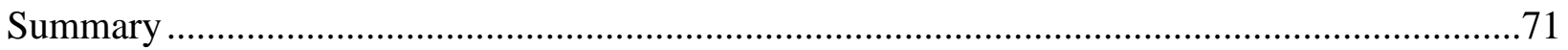

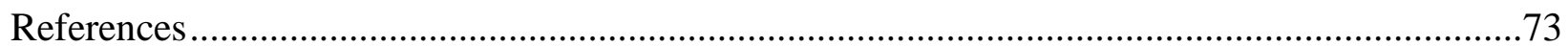

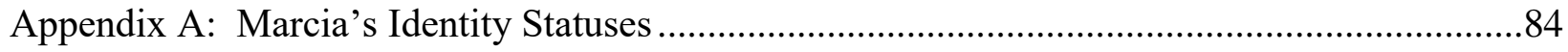

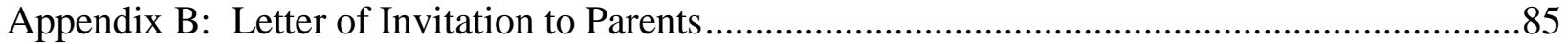

Appendix C: Letter to Homeschool Support Group Coordinators ............................................86

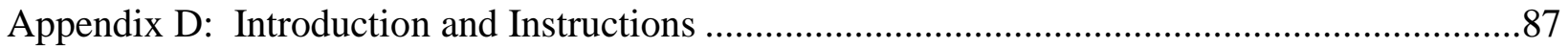

Appendix E: Parental Information - Demographics ................................................................8

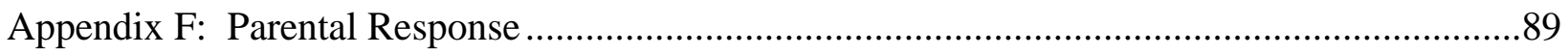

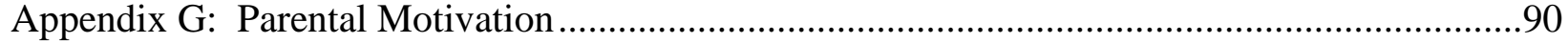

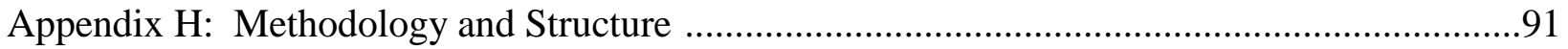

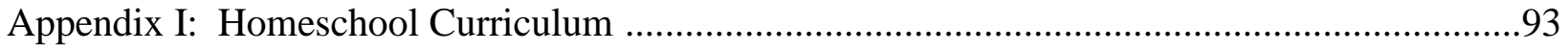

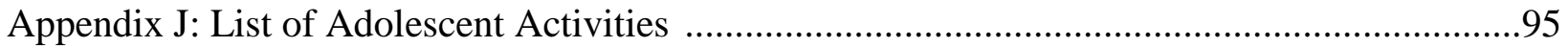


"Be who you are and say what you feel because those who mind don't matter and those who matter don't mind" (Baruch, 1947)

\section{Chapter 1: Introduction to the Study}

\section{Overview: Adolescence and Identity Formation}

During adolescence, individuals search for a sense of self that provides inner meaning and understanding of who one is as a unique being and who one is in a societal context. Adolescence occurs between puberty and the early to mid-twenties (Muuss, 1988). It has been characterized as a developmental period "often contradictory in direction and qualitatively heterogeneous" (Blos, 1962, p. 52). It is a time marked by heightened responsibilities, increased independence, and increased expectations during which the adolescent's brain is maturing and developing a greater capacity for independent problem solving (Steinberg, 2008). The formation of life goals come to the fore in one's thought processes (Nauta \& Kahn, 2007). A complex role image surfaces that "summarizes one's past, gives meaning to one's present, and directs one's behavior in the future" (Adams, Gullota, 1989, p. 231). The emerging image of self which develops during adolescence does not occur in isolation, but in an individual's contextual settings (Bronfenbrenner, 1979).

It is widely accepted that safe environments which provide opportunities for developmentally appropriate exploration and activities are integral to a positive development of self. McMahan (2009) identified the primary contexts necessary as families, peers, culture, and schools. Given the significance of contextual factors upon a healthy development of self, it is crucial to examine the fundamental processes integral to education provided in the home and how those processes facilitate or hinder the formation of identity, particularly in light of the dramatic increase in homeschooling during the last two decades (Gaither, 2008; Murphy, 2012; Ray, 2009). Taylor (1986) states that "Any substantial educational movement must also be evaluated for its effect upon self-concept" (p. 13). Kunzman (2009) articulated the need to examine and understand the impact of homeschooling in a societal context, "Parents and children 
have profound interests at stake in the shape of a homeschooling education. But the outcome matters to broader society as well, both in terms of having economically self-sufficient members and citizens committed to a healthy democracy" (p.11). The homeschooling process including parental motivation and methodology, and the outcomes associated with homeschooling are necessarily integral constituents of an adolescent's formation of identity.

It is during this time that the young person experiences an intense drive for autonomy and is expected to form a sense of self that provides meaning and purpose to life (Erikson, 1963). It is commonly viewed as a time of on-going change, adjustment, and transformation. The brain undergoes dynamic changes during adolescence, particularly the frontal lobes which are responsible for executive functions governing self-control, judgment, emotional regulation, organization, and planning (Sowell, et al. 1999). Teens become increasingly capable of inductive and deductive reasoning (Kuhn, 2009).

The development of a sense of self, or formation of identity, is a process that occurs "gradually, incrementally, and often unintentionally" (Josselson, 1991, p. 15). This transitory stage is fluid, rather than fixed, meaning that it does not progress in a straight line nor proceed at a steady pace (Blos, 1962). In other words, it is typical, understandable, and even expected for adolescents to progress toward a goal or specific direction, then digress in another direction or toward a different goal, only to turn back toward the earlier goals, but perhaps in a new way. According to Kroger, (2004), an adolescent's social and cultural context plays a vital role in the formation of identity by regulating attitudes and behavior. Adolescents commonly experiment with different looks, interests, activities, and ideologies in establishing individual identities. Social influences and expectations change during this time offering adolescents a, "new array of [personal] choices and decisions" (Steinberg, 2008, p. 269). They become very conscious of similarities and differences between themselves and their peers and may respond to the differences in unpredictable manners. 
Historically, this transitory time has been described as a time of crisis and disequilibrium, punctuated by frequent uncertainty, a sense of distress, and feelings of incompleteness (Adams, Abrahams, \& Markstrom, 1987; Adams \& Marshall, 1996; Markstrom-Adams, Ascione, Braegger, \& Adams, 1993; Markstrom, Berman, Sabino, \& Turner, 1998). Writing from a psychoanalytic perspective, Blos (1979) described adolescence as a, "period of psychological restructuring” (p. 325) involving concomitant chaos, mood swings, turmoil and crisis, and experimentation. Acknowledging that many adolescents experience stress, tension, and rebellion, Bandura (1964) emphasized that the related behaviors are a result of, "cultural conditioning and social expectation rather than inevitable developmental phenomena characteristic of adolescence per se" (p. 224). Eccles et al. (1993) note that although many adolescents experience storm and stress, most pass through this transitory time without excessively high degrees of turbulence.

Sukarieh, and Tannock (2011) posited a recent societal change in perspective regarding the nature of adolescent development. The change is attributed to a focus on potential positive associations and related outcomes rather than risk behaviors and pathology. They summarized their premise, "The essence of this shift has been the move from negativity to positivity in representations of the youth" (p. 675). Likewise, Hershberg, Johnson, DeSouza, Hunter and Zaff (2015) and Lerner, Jacobs and Wertlieb (2003) regarded and characterized adolescence from a positive, optimistic perspective, stressing the associations between contributions to societal causes and/or institutions and positive psychosocial outcomes. Regardless of philosophical, psychological, or academic orientation, there exists interminable anecdotal evidence to substantiate adolescence as a time of change.

The change, uncertainty, and possible sense of disorientation concomitant to the formation of identity frequently precedes a deepening discovery of one's self. It is the quest for self-discovery which drives the young person to explore a personal ideology. The intense 
physical, social, moral, and intellectual growth experienced by adolescents can elicit chaos, confusion, and turmoil for the family as well as the teen (Leigh \& Peterson, 1986; Smits, Soenens, Luyckx, Druiez, Brozonsky \& Goosens, 2008; Yablonska, 2013).

\section{Statement of the Problem}

The journey of becoming oneself, of forming a personal identity, does not happen in isolation, but rather in a social context. Adolescents depend on feedback from family and friends as indicators of others' perceptions and as a part of the iterative process of identity formation. This is both a personal mental process and a social process wherein one is constantly processing environmental cues, opinions, observations, and reactions from friends and family (Schmitt, Dayanim, \& Matthias, 2008). Leary (2005) proposed that a positive self-view, which is integral to healthy identity formation, springs from general positive social interactions with relevant others. Socialization Theory stresses the importance of individuals' interactions within their environments as crucial to development and identifies socialization as, "the process by which a child acquires the skills, patterns, behaviors, values, and motivations needed for competent functioning in the culture in which the child is growing up" (Maccoby, 2007, p. 13).

The prominence and value of peer relationships and peer groups increases significantly during adolescence (Reitz, Zimmerman, Hutteman, Specht \& Neyer, 2014). The peer group becomes increasingly more influential in the individual's quest for identity, frequently providing assistance, direction, and feedback regarding one's choices, behaviors, and personal attributes (Muuss, 1988). Blos (1962) asserted that during adolescence, there is less dependency on parental approval and assurance for feelings of worth and significance than there was in childhood. He further stated that the earlier dependency is replaced by social experiences that provide esteem and approval.

Although strong peer friendships have been shown to provide significant support for emotional stability (Chang, 2015), Neufeld and Mate (2014) contended that socialization bereft 
of an adult as a primary attachment figure leads either to interpersonal conflict or to a suppression of individual identity. Numerous researchers have acknowledged the value of the parents' role in the socialization of children (Grusec \& Davidov, 2010; Harris, 2000;

MacDonald, 1987). Elkind (1988) asserted that socialization occurs largely in the home because "the family is a school of human relations in which children learn how to live within society" (p. 121). Grusec and Davidov (2010) similarly noted that socialization is largely dependent upon and occurs within family. Given the necessity of socializing experiences, which include peer relationships, in the formation of identity and given the significance of and integral nature of the family's role in these experiences, it can thus be conjectured that the foundation for healthy identity formation resides within a family context that nurtures healthy social relationships. This premise is fundamental in understanding the potential facilitative effect of homeschooling upon the process of identity formation.

Erikson stressed the necessity for adolescents to find people and ideas in which to have faith. Common to humankind and most markedly present during adolescence is the need to feel special and unique, accompanied by a need to belong (Erikson, 1963). How can one belong if one is unique? It is that the quest for identity involves finding people, ideas, and ideals with which one can identify and eventually commit. Successful identity achievement requires positive parental involvement, meaningful peer interactions, and opportunities for societal interaction and involvement. Adams, Dyk and Bennion (1990) supported the premise that nurturing parents promote high quality exploration leading to subsequent commitment of a personal ideology, a hallmark of identity achievement. Proponents of home education assert the home to be the most appropriate educational context by providing an environment free of the distractions caused by what many refer to as social ills prevalent in the public school system (e.g., bullying, violence, ostracizing by cliques) thus facilitating freedom of expression (Davis, 2005; Gaither, 2008; Gathercole, 2007; Murphy, 2012; Ray, 2009). Additionally, homeschool 
parents share the belief that the flexibility in scheduling expands the availability of opportunities for engagement in the larger environment (Gaither, 2008; Murphy, 2012; Ray, 2009). Parental support for and encouragement of autonomy unquestionably available in the day-to-day homeschool setting provides a basis for exploration integral to the formation of identity.

Attachment theory research has affirmed the need for an adolescent to have a sense of connectedness with parents, along with the need for parents to provide encouragement of the adolescent's independent and autonomous behavior. Further substantiation of the crucial nature of parent-adolescent connectedness is found in Family Systems Theory. Differentiation, an integral component of identity formation, is inextricably tied to parental support and parental encouragement of adolescent autonomous thought and behavior. Proponents of homeschooling suggest that the close connection inherent in the abundance of day-to-day discussions, interactions, and activities provides a perfect foundation for adolescent individuation and development of self.

Homeschooling is an avenue through which parents can provide an environment conducive to exploration crucial in identity development. For example, Griffith (1998), a home schooling parent and author, states, "Keeping up with their changing needs isn't that difficult because I am with them and aware of these changes, so it just flows from living together (p. 153). Griffith (1998) expanded on the inherent suitability of the homeschool environment in fostering the formation identity in quoting a homeschool parent: "I think that to have a good, respectful relationship with our teens we need to be sensitive to their right to choose what they are learning and how they want to pursue it" (p. 155).

There has been a huge pendulum swing in the societal response to the ever-growing educational choice by many families to homeschool their children. What was once considered to be a fringe educational movement has become a viable alternative for families who are searching for an option other than public, private, or religiously-affiliated educational settings. "The 
growth of the homeschool movement represents the attempt of a widely diverse group of parents to decide how their children will be educated, what values they will learn, and which socialization experiences they will encounter” (Mayberry, Knowles, Ray \& Marlow, 1995, p. 39).

Although imperfect and, in many cases, lacking ardent research methodology, there exists a growing body of research substantiating the academic success of many homeschooled students. However, there is a considerable dearth related to measures of psycho-educational and socioemotional development of young people who are homeschooled, thus it is not possible to postulate any connections between social and psychological factors such as learning, behavior, self-perception, self-awareness, personality, and environment. To date, there exists no known research ( $\mathrm{i}$ e., to this researcher) examining the psychosocial phenomenon of identity formation in adolescents who are homeschooled. Thus, an examination of homeschooling processes and adolescent identity formation is necessary. As a society it is important to critically evaluate all of the educational venues available in order that stakeholders can make informed choices when establishing policy. Equally significant is the parental need for an unbiased examination of the process.

\section{Statement of Purpose}

Whatever the venue for learning (parents' home, homeschool co-op, or other), whatever the level of structure (from an 'unschooling' approach to a rigid schedule), whatever the curricula (a parent-selected 'mix and match' approach, school district texts and materials, 'canned' curriculum with lesson plan guides, cyber-school, or self-directed paces), there exists a common undeniable concern; a foundation for learning must consider the needs of the learner in the implementation of the educational program. All developmental domains must be considered in addressing the needs of the learner. 
The need to establish one's own identity is of undeniable significance during adolescence and has been identified by Erikson $(1959,1968)$ as the key developmental task of adolescence. Although identity formation occurs throughout one's lifetime, adolescence is the first time that individuals consciously begin to think about how personal identity may affect their lives. Identity achievement, which is seen as the successful completion of this developmental task, leads to feeling valued by self and others (Erikson, 1959). A fully-integrated self has been associated with a flexible and efficient coping style (Marcia, 1966). It is commonly accepted that an understanding of who one is as an individual is basic to growth, understanding, and life satisfaction.

\section{Overview Summary}

A personal identity is a cohesive sense of self, and it includes beliefs about group identities, institutions, values and goals. In the process of identity formation, adolescents are attempting to answer the question, "Who am I and where do I fit in?" There are two basic processes involved in the formation of one's identity: (a) exploration, which includes testing new roles, looks, activities, possible career choices, sexuality, beliefs, and interests and (b) commitment, which involves aligning with or committing to a particular ideology. Exploration is necessary for identity achievement but can be unsettling and uncomfortable.

It is crucial that adolescents be provided with a supportive environment that encourages questions, discussion of differences, and exploration of interests. Parents who homeschool their adolescent children believe the home to provide such an environment. This study will explore the potential facilitative role of homeschooling in addressing the psychosocial needs of adolescents, specifically the formation of identity. Instruction in the home is most often provided by the mothers, thus it was appropriate to focus this study on the perceptions of mothers who homeschool their adolescent children. 
The paucity of research specific to psychosocial development of homeschooled adolescents necessitated a broad search of related literature and exploration of other sources to ensure integrity in analyzing and synthesizing the information. Numerous sources were researched in exploring identity formation of adolescents who are homeschooled. Conversations with homeschooling parents facilitated an understanding of the motivations and methodologies employed in the process, which in turn provided a valuable starting place for research. A variety of texts written by homeschooling parents were used to further gain an accurate perspective from the view of those who are currently involved in the process. Search parameters through various library search engines included the following terms in isolation and/or combined with homeschooling; statistics, achievement, outcomes, socialization, identity development, identity formation, family relationships, adolescent-parent relationships, adolescent attachment, selfconcept, adolescence, peer influence, individuation, differentiation, history, methodology, motivation, state regulation, criticism, detriments, advantages, disadvantages, reasons, rationales, demographics, societal and civic engagement, and regulations. In addition to an exploration of Erik Erikson's publications regarding psychosocial development, search terms associated with other relevant theoretical perspectives included: identity statuses, Family Systems Theory, Social Learning Theory, and Attachment Theory. 


\section{Chapter 2: Review of Selected Literature}

\section{Foundational Overview}

The purpose of this study was to understand how homeschooling can support adolescent identity formation. Therefore, a review of literature relevant to identity formation and to the homeschooling process will be presented. This chapter will begin with a definition of identity, followed by an examination of several theoretical perspectives and conceptual frameworks foundational to the understanding of identity formation. Following will be a brief history of homeschooling in the United States, focusing primarily on parental motivation and parental methodology. The research questions form the last section of this literature review.

\section{Identity Defined}

Identity refers to one's sense of self and forms in response to both internal and external factors (Erikson, 1959, 1968). This formation is a dynamic and complex process (Erikson 1968, Marcia, 1980). Moshman (1999) posited that there is not a universally-accepted definition of identity yet acknowledges that identity is, “... at least in part an explicit theory of oneself as a person" (p. 78). Commonly, identity is generally thought of as those qualities that make individuals who they are and sets them apart from or differentiates one from another. Personal identity develops over time and can evolve, sometimes drastically, depending on the direction one chooses in life. Broadly speaking, identity refers to the sense of who one is as an individual and as a member of society. Identity formation is a dynamic and complex process. Considered one of the most prominent authorities on identity formation Erikson (1968) defined identity as:

the awareness of the fact that there is a selfsameness and continuity to the ego's synthesizing methods, the style of one's individuality, and that this style coincides with the sameness and continuity of one's meaning for significant others in the immediate community (p. 50). 
Erikson (1959) viewed identity as a synthesis, on the part of the ego, of external (environmental, social, and familial) and internal, or intrapsychic, forces striving to find equilibrium. In other words, identity is that which preserves continuity in one's life experience. It allows an individual the opportunity to link the past with the present, leaving behind those values that no longer match the currently held and/or evolving ideals, while at the same time holding onto those ideals which provide meaning, purpose, and direction. In writing from an Eriksonian perspective, Josselson (1991) provides further a succinct, operational definition of identity: Identity is the stable, consistent, and reliable sense of who one is and what one stands for in the world. It integrates one's meaning to oneself and one's meaning to others; it provides a match between what one regards as central to oneself and how one is viewed by significant others in one's life. (p. 10).

Simply stated, everyone needs a sense of uniqueness and a sense of belonging. Each individual needs to develop a sense of autonomy that is separate from others (Adams \& Marshall, 1996). Basing her perspective on numerous interviews with adolescent girls and their mothers Apter (2009) stated, "One of the main tasks of adolescence is to achieve an identity—not necessarily a knowledge of who we are, but a clarification of the range of what we might become, a set of selfreferences by which we can make sense of our responses and justify our decisions and goals" ( $p$. 112).

The adolescent identity crisis also involves a struggle with religious and political ideologies (Erikson, 1968). Whether the adolescent has any specific religious and/or political convictions, whether there is any involvement in, or expression of religious, political, and/or civic activity, and the extent to which the adolescent's convictions, expressions, goals, and activities differ from those of parents, are all critical considerations in the formation of identity (Parsons, Nalbone, Killmer \& Wetchler, 2007). Amidst these challenges, adolescents are often idealistic and concerned with what is fair and right. In the quest for what is fair and right on a 
personal basis, adolescents must develop a consistency between self-view and how they are viewed by others. The grappling for an assimilation of inner and outer directions is confounded by an instability resultant from conflicting inner and outer demands.

\section{Overview of Theoretical Perspectives}

There are several theories of development from differing perspectives that share notions of stages, transitions, and developmental tasks. Our understanding of the concept of identity formation has been influenced by research from a variety of social science perspectives and academic disciplines (e.g., add some examples in here). While there is a diversity of theoretical perspectives, there is a consistent belief across disciplines in an individual's need for a unique and individuated identity. Constructs relevant to this study will be extrapolated from Attachment Theory and Family Systems Theory to provide reasonable juxtapositions of the day-to-day application of pedagogy in the milieu of homeschooling. Tenets of these theoretical models are presented to provide clarity in understanding the relationship between an adolescent's journey to self and the experience of being educated in the home.

While these constructs are significant to an understanding of adolescent development from a broad perspective, Erik Erikson's $(1959,1968)$ theory of psychosocial development provides the conceptual understanding of the phenomenological constituents relevant to identity formation thus forming the basic theoretical foundation for this study. Marcia's (1966) operationalization of Erikson's work in categorizing identity statuses provides additional understanding of the process. Constructs from the supplementary models facilitate the formation of the questions in this qualitative study. Discussion begins with an examination of Erikson's model, followed by an application of Marcia's identity statuses. Presented next are the supporting theoretical models, followed by a synthesis of the various perspectives.

Psychosocial theory. Although his primary writing providing elucidation of identity formation is a half-century old, Erikson's (1968) model of psychosocial development continues 
to have a profound impact on our understanding of the phenomenon known as identity

formation. Erikson's psychosocial model is based on the epigenetic principle which says that an individual's identity develops through a predetermined series of stages. Each of the eight stages involve a crisis resultant from conflict between the psychological needs of the individual and the needs of society. A crisis is not what one would generally view as a catastrophic event, but rather as an intersection or turning point in one's developmental journey. Each stage-specific crisis must be resolved for the individual to successfully navigate subsequent stages. Erikson sees each personal and social crisis as potentially conducive to psychosocial growth. The fifth stage, identity versus role confusion, occurs during adolescence and results in identity achievement or role confusion.

Erikson (1963) described the adolescent mind as, "essentially a mind or moratorium, a psychosocial stage between childhood and adulthood, and between the morality learned by the child, and the ethics to be developed by the adult" (p. 245). Identifying the dichotomous role of this stage Erikson (1968) further stated, "In no other stage of the life cycle, then, are the promise of finding oneself and the threat of losing oneself so closely allied" (p. 244). The successful resolution of the identity crisis of adolescence involves replacing childhood identifications with one's own self-defined set of identifications and commitments whereas unsuccessful resolution of a crisis results in future psychological instability in some area (Erikson, 1968). Bosma and Kunnen (2001) described the conflict involved in the crisis as transactions through which an individual attempt to resolve the conflict by, "adjusting their interpretation of the situation in such a way that it can be assimilated into their existing identity" (p. 63). In the absence of assimilation, the conflict will continue until such time as there is an accommodation or a change in identity (Bosma \& Kunnen, 2001). It is through navigating this process that one establishes an individual identity. 
Marcia (1966) extended Erikson's initial treatise of identity formation and established a model of identity formation coining the term "identity status" to label and describe four unique stations along the continuum according to dimensions of exploration and commitment. Generally regarded by researchers as personality outcomes, the statuses are also conceptualized as a process (Smits, Soens, Luckyx, Druies, Brozonsky \& Goosens, 2008). In following and expanding on Erikson's work, Marcia asserted that certain situations and events serve as catalysts in creating internal conflict (or crises) which in turn causes adolescents to examine and question their values, beliefs, and goals. Exploration can be understood as questioning which leads to an exploration of new possibilities and intentional exposure to novel experiences in order to gain a personal perspective which in turn promotes the formation of new beliefs, the adoption of personal values, and the ability to make independent choices (Marcia, 1966). Commitment is defined as, "the degree of personal investment the individual exhibits" (Marcia, 1966, p. 551). Josselson (1991) asserts that, "these commitments become the core of the newly wrought identity" (p. 29). The statuses defined by Marcia (1966) provide an indication of where an adolescent is at a given time on his/her pathway toward identity achievement (Figure 1).

The first identity status, identity diffusion, describes adolescents who have neither explored nor committed to any particular identity. This status is characterized by a lack of life goals evidenced by a low level of exploration and a low level of commitment. They tend to be passive and try to avoid discomfort. Rather than experiencing anxiety, they may try to escape new experiences. Adolescents at this status may obtain part-time employment for the sake of the pleasure(s) associated with the money earned, but not as part of a general career exploration.

The second identity status, foreclosure, is represented by a low degree of exploration but a high degree of commitment. Youth in this status commit to an identity that is derived from the values and beliefs they have been taught and are acceptable within their family and culture. They know what they believe or perhaps, what they have been taught to believe, but are not able 
to explain the basis for those beliefs from a personal perspective. Many young people at the second status begin to follow in the footsteps of other family members.

The third identity status is moratorium, represented by a high degree of exploration but a low degree of commitment. Youth at this status are in the midst of discovery by exploring and experimenting with different values, beliefs, and goals. However, they have not yet made any commitments regarding which principles to embrace as their own. Teens at the third status may appear to rebel against everything they very recently embraced, yet the rebellion is borne not of anger or hostility, but rather from the "need to know" on a personal basis. Parents can become quite exasperated when their teen exhibits displeasure (with events, situations, and/or people) without being able to provide an explanation for the displeasure.

Identity achievement is the fourth identity status and is represented by a high degree of exploration and a high degree of commitment. Adolescents at this status have decided what values and goals are important to them personally and which ones they will use to direct their lives. Identity achievement does not typically occur until late adolescence.

Erikson repeatedly stressed throughout his writings the connection between an individual's psychological development and the social context under which it develops (1959, 1968, 1980). Regarding the impact of culture, Erikson said that, "we deal with a process located in the core of the individual and yet also in the core of his communal culture" (1968, p. 22). Identity cannot develop in isolation; thus, it is critical to examine the environmental and contextual factors associated with the process. In so doing, consideration is given to constructs of relevant developmental models.

Attachment theory. Germane to an understanding of identity formation is a consideration of the significance of parent-child attachment as explained by Bowlby (1969, 1988). Attachment theory affirms the need for an adolescent to have a sense of connectedness 
with parents, along with the need for parents to provide encouragement of the adolescent's independent and autonomous behavior.

Armsden and Greenberg (1987) found that secure attachments were shown to be associated with greater exploration in both toddlers and adolescents. Bowlby $(1969,1988)$ said it is the early connection with parents that provides the foundation for subsequent connection with others and that exploration begins from a secure base formed in infancy and childhood. Thus, attachment theory affirms the need for an adolescent to have a sense of connectedness with parents, along with the need for parents to provide encouragement of the adolescent's independent and autonomous behavior.

Adolescents become increasingly capable of simultaneously comparing, contrasting, formulating, and representing multiple perspectives, beliefs, values, and goals, which all serve to direct decisions and behaviors. In doing so they develop a more differentiated sense of self and significant others, as well as a more differentiated view of the world, including how they see themselves fitting in and finding a place in the world. The push-pull characteristic of this process can produce both intrapersonal and interpersonal conflict. Galambos, Barker, and Almeida (2003) asserted that conflict arises in healthy parent-adolescent relationships and can be viewed as part of the on-going negotiation involved in the adolescent's self-discovery, maturing and assuming of increasing responsibility. Allen, Moore, Kuperminc, and Bell (1998) expanded on the significance of bidirectional communication, "Adolescents who were relatively more able to talk about attachment experiences in ways that represented balance, perspective, autonomy, and open acknowledgement of the importance of attachment were more likely to be socially accepted by peers ...” (p. 1414). Thus, it can be suggested that the quintessential feature of attachment security is demonstrated by the capability and desire of parents and their adolescent children to maintain connection while disagreeing on significant and crucial issues. 
Also significant to an adolescent's on-going development of self and sense of security are the relationships with peers. It is generally accepted that seeking support and affirmation from peers increases during adolescence, yet while there is an increased desire for peer acceptance, Greenberg, Seigel, and Leitch (1983) found that the quality of attachment to parents was more significant to measures of well-being than was the quality of attachment to peers. Somewhat conflicting results were found by Hay and Ashman (2003) which showed peer relationships to be more influential to an adolescent's emotional stability than parental relationships. In both studies the quality of relationships, whether parent or peer, was found to be a significant factor related to the level of influence. The influence and impact of peer relationships during adolescence cannot be underestimated. Peer relationships that promote positive behavior and healthy lifestyle choices are vital in the adolescent journey of becoming oneself. Dekovic and Meeus (1997) contended that, "a positive self-concept and warm supportive parenting each contribute unique variance to satisfactory peer relations" (p. 163) thus demonstrating the importance of positive parent relationships as foundational to positive peer relationships. According to Kroger (2007), "Peer support and the mirroring of one's values in combination with supportive relationships with one's parents serve essential functions in the process of self-definition" (p. 63). Advocates of homeschooling posit supportive parenting and the opportunity to provide guidance in the formation of peer relationships as integral to the homeschool milieu (Davis, 2005; Gaither, 2008; Gathercole, 2007; Murphy, 2012).

Paterson, Pryor, and Fields (1995) supported the contention that parents remain adolescents' most significant attachment figures. In a review of literature from a neurocognitive perspective, Moretti and Peled (2004) affirmed the positive effects of a secure parent-adolescent attachment in concluding that securely-attached adolescents are less likely to engage in excessive drinking, drug use, and risky sexual behavior. These securely-attached young people also experienced fewer mental health problems (p. 553), an assertion corroborated by Allen, Moore, 
Kuperminc and Bell (1998). Connectedness, in the sense of bidirectional attachment, within the family unit has been demonstrated to be an extremely significant factor in reducing negative outcomes (Resnick et al., 1997).

The primary characteristics of connectedness are identified as those evidenced through parents and children sharing their thoughts and feelings, spending time together, frequency of discussions, parental presence with the children, parental attendance at school-sponsored events, and parental encouragement of their children's autonomous behavior (Lezin, Rolleri, Bean, \& Taylor, 2004). Family connection during adolescence has been associated with self-acceptance and positive relationships at midlife as shown in a longitudinal study by Bell and Bell (2009). Doctors (2013) provided clinical evidence to support the contention that secure attachments between parents and children established in childhood facilitates further evolution of the bond, thus promoting the adolescent's sense of self and other within the parent-child relationship. Likewise, Bell and Bell (2009) described parental caregiving during adolescence as, "that which provides acknowledgement and validation of the child's ideas, feelings, and accomplishments" (p. 475).

Allen, Hauser, Bell, and O’Connor (1994) stated, “In healthy parent-adolescent relationships, parents provide structure with enough flexibility that adolescents can securely engage in identity exploration, and adolescents reciprocate by establishing autonomy without sacrificing relatedness" (p. 182). Amid the typical physical, emotional, neurocognitive, and cognitive changes concomitant to adolescent development, it can present a challenge for parents to balance the encouragement of an adolescent's increasing need for autonomy with the appropriate amount of supportive connectedness. Communication that provides the opportunity for healthy conflict and resolution is vital, as is the wisdom and patience in choosing which battles are truly worth engagement. 
According to Beyers and Goosens (2008), it is the bond with parents which provides an adolescent with the sense of acceptance, freedom, and comfort necessary for the development of autonomy. As autonomy is developed through the freedom to experience and express one's thoughts in words and/or behaviors, the adolescent is able to question previously held beliefs and explore new interests, ideas, and values. Thus, as the secure connection with parents sets the stage for the development of autonomous thought and behavior, so the development of autonomy sets the stage for the exploration necessary for the formation of identity.

Family systems theory. The importance of understanding the family as a system with an emphasis on the relational aspect of development is stressed by Bowen (1978) and provides additional insight into a contextual understanding of identity formation. According to Bowen (1978), the foundations of a "self" are inborn, but it is an individual's family relationships during childhood and adolescence that are primarily responsible for determining how much "self" an individual develops. Bowen defined differentiation, a key element of identity formation, as the ability to think independently while also maintaining meaningful connections to others. Differentiation is characterized by an individual's recognition of realistic dependence on others and the ability to consider the thoughts, opinions, and interests of others while at the same time making independent decisions.

Yablonska (2013) found that the most favorable conditions for identity formation are determined by “optimal levels of family cohesion and adaptability, such upbringing characteristics as positive interest, democratic style of parenting, acceptance of own children, reasonable autonomy, and a high degree of parents' consistency during upbringing" (p.39). In a study that examined the relationship between short-term changes in parenting and identity formation during late adolescence, Beyers and Goosens (2008) found that parenting style and identity formation are interconnected and recommended that parents provide a warm, supportive environment which encourages "adolescent searching for self-evaluated and self-defined 
answers" (p. 167). Ideally, there should be a balance between support and independence. Parents need to communicate a sense of understanding and acceptance as the adolescent experiments with new ideas, roles, and activities.

From a Family Systems perspective, positive parental influence is not only necessary for healthy psychosocial development, but also lays the foundation for exploration that is essential to the development of future relationships, social interactions, and commitments. For healthy resolution of this crisis, it is imperative that adolescents are provided with an environment that fosters exploration, encourages questions, accepts resistance to status quo, stimulates critical thinking and also provides the boundaries necessary for the adolescent to make socially and emotionally healthy decisions.

\section{Homeschooling}

Homeschooling is a growing and powerful social and educational phenomenon (Murphy, 2012). It is an alternative form of education whereby parents assume responsibility for the education of their children. A comprehensive examination of the literature supports the conclusion that homeschooling defies a succinct definition and is not as simple a process as it may appear on the surface (Murphy, 2012). If it is possible to capture the essential essence of homeschooling when describing those involved in the process, the methodologies they use, and their motivation for homeschooling, perhaps the most appropriate descriptor is "diverse."

Homeschooling practices vary in methodology, curricula, scheduling, parental motivation, degree of structure, and level of peer interaction. Understanding the process of homeschooling requires identification of those involved thus a demographic overview is presented first. Following demographic information is a brief review of the history of homeschooling which provides a contextual awareness foundational to understanding the process. It has been suggested that parental motivation and methodology are inextricably linked to outcomes warranting an examination of these factors. Following a description of motivational 
factors and methodologies is a description of the challenges associated with the paucity of empirical research. A review of relevant research studies is presented next, followed by extrapolations pertinent to this study.

Homeschooling demographics. Just as is the case with any other educational choice, such as private school, public school, charter school, or religiously-affiliated school, there is great diversity amongst those who engage in the process of homeschooling. If one were to "hang a label" on homeschoolers as a group, it would necessarily indicate diversity in all domains of life. However, regardless of motivation for homeschooling and methodology used in the process, one common belief of most, if not all, is the conviction that the home provides the most appropriate venue for education in all areas of growth and learning. According to Marlow (1994),

Home education represents an exit from the formal education system, an exit based on a complex set of needs, motivations and expectations that are often idiosyncratic when examined individually but are united collectively into an organized and sophisticated sociopolitical movement (p. 440).

Gaither (2008) cites sociologist Zygmunt Bauman (2000) in describing homeschooling families as a group, "He has labeled the cultural condition where each individual is free to do as he or she pleases in an endless and boundless present, but absent compelling social norms that would make such choices meaningful a "liquid modernity" (p.225). Gaither (2008) describes homeschooling as, "part of this move to liquidity, as the grounded, industrial-era education of the past gives way to a cybertopian form of libertarian education" (p.225). Simply said, it can be postulated that homeschooling families as a group seek to maintain autonomy and freedom to make educational choices for their children.

In May of 2015, the U.S. Department of Education (2013) released data provided by the National Center for Educational Statistics (NCES) which contained a breakdown of the yearly 
number of students who were homeschooled from 2003 to 2012. According to the report, there were 1.77 million children being homeschooled in grades $\mathrm{K}$ through 12 in 2012 . This figure represented a $61.8 \%$ increase from 2003.

Although ideological orientation, religious beliefs, and methodological approaches vary amongst homeschool parents, there exists some measures of central tendency. Researchers (Lines, 2000; Muntes, 2006; Murphy, 2012; Ray, 2010) have consistently found that homeschooling parents are generally well-educated. They are usually within the middle socioeconomic class (Bauman, 2002; Belfield, 2005; Ray, 2005; Wartes, 1990). Murphy (2012) reported the majority of homeschoolers to be from two-parent families. In studies of homeschool families, Muntes (2006), Ray (2004), Ray (2010) and Rudner (1999) estimated marital cohesiveness (defined as two-parent families) to be between $87-98 \%$, as measured by self-report surveys. According to the U. S. Census Bureau (2014) only 58\% of children in the general population, aged 18 and younger, were living in two-parent families in 2010.

Another characteristic shared by many homeschooling families is a larger than average family size (Rudner, 1999.) In his most recent analysis of demographics related to homeschool families, Ray (2010), provided the following breakdown of number of children in each household: one (6.6)\%, two (25.3\%), three (26\%), four (20.2), and more than four (14.9\%).

In terms of race and ethnicity, Murphy (2012) provided data demonstrating that whites are disproportionately represented in the population of homeschooling families. However, numerous researchers (Bauman, 2002; Gaither, 2008; Ray, 2005; Taylor, 2005) have documented a growing diversity in the ethnicity, culture, and race of those who homeschool.

Homeschooled adolescents are young people whose parents have diverse reasons for homeschooling, embrace varying instructional methodologies, utilize differing curricular materials, and represent divergent ideological, political, and religious orientations. What began as a movement primarily represented by liberal progressives has become embraced by the 
conservative right in more recent years (Murphy, 2012). Parents representing differing ideologies have joined forces to provide the education they deem appropriate for their children (Gaither, 2008; Murphy 2012). This in part, explains the increase of families choosing to homeschool.

An example of the dichotomous nature of those engaged in home schooling can be seen in two very different groups who both view the home as the most appropriate educational venue for achieving their goals; those who want to shield their children from what they view as negative influences of over-crowded multicultural classrooms and those who intentionally seek diverse cultural experiences over which they have control. The uniting of divergent views can also be seen in the desire for academic excellence. Those who follow the practice of "unschooling" (i.e. little or no parent-provided structure) view the inherent opportunities for selfdirected exploration as tantamount to genuine learning. On the opposite end of the methodological spectrum are those who seek academic excellence in a structured, almost "school-like" environment within the home, believing that the absence of academic and social distractions, provides an environment conducive to optimal intellectual and emotional growth and learning.

History of homeschooling. According to Stevens (2001), the homeschool movement "straddles two cultural landscapes" (p. 96). At its core in the initial stages, homeschooling was a process of establishing and preserving the freedom of educational choice which frequently involved many ideological, social, and educational battles for those who educated their children at home. There are differing views regarding the inception of the modern homeschooling movement. Lines (2000) identified the 1950's as the beginning of the contemporary homeschooling movement and classified the individuals who began the movement as liberals and educational progressives. In other words, the early pioneers tended to hold anti-establishment views on educational practice and advocated for educational reforms that embraced 
constructivist views and followed John Holt, who believed that compulsory education destroyed a child's natural curiosity and created a fearful desire to please the teacher (Cochran, 1999; Gaither, 2008; Murphy, 2012; Yuracko, 2008). The anti-establishment mantra that served as a catalyst for many in the early homeschool movement, particularly those with a liberal political orientation (in the 1960's and 1970's) has evolved into a more generalized belief that the benefits gained through individualization available through home schooling, far outweigh any possible benefits available through the institutionalization in public schools (Murphy, 2012). The respect for professional advice gave way to skepticism and rejection of authority. The battle for autonomy in educational choice often resulted in a pervasive mistrust, skepticism, and wariness of those involved in traditional educational practices, such as assessment and research, as will be described.

Gaither (2008), Isenberg (2007), and Ray (2009) suggested that the modern homeschooling movement began in the 1970's and was represented by two differing ideologies. One group was motivated by religious beliefs and concerns, and a fear that their local schools would teach a curriculum contrary to their fundamental religious beliefs. The second group, labeled by some as ideologues, believed a superior academic education could be achieved through homeschooling. Gaither (2008) noted that many of the ideologues represented a countercultural philosophy, maintaining that the home environment could better provide the freedom to learn than could the public school. The anti-establishment mantra that served as a catalyst for many in the early homeschool movement, particularly those with a liberal political orientation (in the 1960's and 1970's) has evolved into a more generalized belief that the benefits gained through individualization available through home schooling, far outweigh any possible benefits available through the institutionalization in public schools (Murphy, 2012). The early pioneers on the far-right of the political spectrum who began by "riding the crest of the wave against secularism and its ill-effects on children and their families" (Murphy, 2012, p. 35) have 
evolved into a more inclusive group religiously while maintaining a distinct separation from traditional education.

Together with Holt's admonition to give children an opportunity to display natural curiosity another voice rose to prominence in advocating the benefits of home education. Dr. Raymond Moore, an analyst of the U.S. Department of Education, advocated a "better late than early approach" to education, saying that children should remain in the home environment until at least the age of eight (Davis, 2005, p. 76). Moore insisted that children were being forced into structured, strict settings thus stifling their ability to learn. Together with his wife Dorothy, the Moores conducted research comparing academic performance of children who began attending school at younger ages (five to seven years of age) with those who delayed attendance until later (ages eight to 10). The results of the study demonstrated that the children who began later quickly caught up and even surpassed the performance of the children who started earlier (Gaither, 2008). A second study which examined neural and sensory-motor development of children, suggested early academic training to be premature (Moore, 1972).

Moore's publications asserting quality time spent with supportive, nurturing parents was more beneficial for a child's development than structured learning environments lent support for an increase in the incidence of homeschooling. According to Gaither (2008), by 1982 Moore had become the most highly respected and sought-after speaker on homeschooling in the country, with numerous appearances before Congress. Although Moore's early work focused primarily on preschool and early child development, through his encounters and on-going research, he and his wife Dorothy soon began to view homeschooling as more than an ideal for young children. They began promoting homeschooling as a viable educational choice for children and adolescents at all grade levels. For parents already concerned about the appropriateness of the social environment of the public schools, the Moore's publications and 
assistance in establishing a system of networking for homeschool families, provided the impetus needed to embark upon the adventure of homeschooling their children.

As more parents began rejecting the view that government-sponsored schools were the ultimate purveyors of learning, homeschooling numbers continued to increase, yet not without numerous challenges. During the 1970's and 1980's there were numerous court battles over parent's rights to educate their children at home (Gaither, 2008; Murphy, 2012; Ray, 2009). Although some of the battles were lengthy and costly, the courts overwhelmingly ruled in favor of the parents. During this time the socio-cultural circumstances were generally conducive to homeschooling for many parents. By the late 1970's many religious conservatives lived in comfortable communities with only one income. Many well-educated mothers, who had become involved community members had growing concerns about the increasing secularization of the public-school system, thus chose to stay at home with young children. There was a deep conviction that individualism, creativity, cultural and personal values, and civic engagement, all believed to be integral to healthy development, could best be taught in a loving, supportive home environment.

Today, homeschooling has become accepted by state legislatures as a viable educational option in all 50 states. There are a variety of reasons cited by parents as motivation for homeschooling with the concomitant ideologies, pedagogy, and curricular materials varying considerably.

Parental motivation. The reasons parents choose homeschooling are varied and complex. Kunzman and Gaither (2013), scholars who have written extensively about homeschooling, questioned the value of categorizing parents' motivations for homeschooling, saying that there is not any completely accurate way to capture and classify every motivating factor, as some are necessarily embedded within others. However, one could reasonably argue that an attempt to study and understand the outcomes associated with the process would be 
incomplete without insight into the associated motivational factors. Numerous researchers have delineated rationales frequently cited by parents as motivating factors in their decisions to homeschool.

A seminal study by VanGalen (1991) examined parental motivations for homeschooling and found two primary distinctions, which she labeled as ideological and pedagogical. The ideologues were those who chose homeschooling as an objection to public/private school teachings and/or from a desire to strengthen the parent-child bond. Those labeled by VanGalen as pedagogues were parents who generally had an educational background and had strong objections to what they perceived as inadequate instruction in the schools. In perusing texts (Bauer \& Wise, 2009; Davis, 2005; Gathercole, 2007) written by homeschooling parents, one finds that rationales generally fall into one of three broad categories: (a) environmental concerns related to the social climate in public schools, (b) the desire to provide religious and moral instruction, and (c) academic concerns (i.e., the belief that a superior academic education can be provided in the home). Issues and beliefs regarding the rights and responsibilities of parents for their child's education were frequently cited yet was generally combined with one of the other three motivating factors.

Several studies (Green \& Hoover-Dempsey, 2007; Mayberry, Knowles, Ray, \& Marlow, 1995) have corroborated the rationales cited by parents as the primary motivational factors. Ray has studied parental motivation numerous times $(2005,2009, \& 2010)$ and consistently found similarly-stated rationales for homeschooling. From the countercultural ideological perspective to the conservative religious philosophical approach, to those with a particularly strong pedagogical preference, the same three primary rationales are cited as rationales for parents' decisions to educate their children in the home (Gaither, 2008; Isenberg, 2007; Murphy, 2012). These three factors have consistently been identified as primary motivational factors since data collection began. Although the format of the questions varied, the data from the National 
Household Education Survey in 1996, 1999, and 2003 affirmed the afore-named reasons as primary motivating factors for homeschooling (Ray, 2009).

Environmental concerns continue to be a growing concern for parents, particularly with the escalation of school violence. Simultaneously, public schools were becoming larger as more and more local community schools closed and merged to create a larger, and purportedly betterequipped educational environment. Yet, some would say that as size increased, the bureaucracy also increased and the personalization and responsiveness to parents decreased, thus leaving many families with a sense of alienation (Gaither, 2008). Issues such as inequality in instruction and social transformation were significant motivating factors for parents already concerned about the environmental climate in the public school. For these ideologues homeschooling was, "not simply the inevitable result of broad social forces" (Gaither, 2008, p. 114), but rather it represented what came to be viewed as an ideal.

Some critics warn that many parents with ideological motivations are sheltering their children from the 'real' world (Lines, 2000; Reich, 2005). Parents maintain that they are preparing their children for the real world through opportunities for active exploration of new ideas, activities, and organizations (Gaither, 2008; Murphy, 2012; Davis, 2005). Davis (2005) suggested a difference between protecting and mentoring, saying that parents are uniquely in a position to determine when their children are ready for specific freedoms and responsibilities, and to provide support through interactive mentoring. Davis (2005) contended that, "When children are put in a situation where the ratio of kids to adults is 15:1 or more, they tend to get more social input from their peers than from adults" (p. 38).

Parents who homeschool for religious and moral reasons do not deny the significance of peer interactions to healthy psychosocial development, rather they choose to assume responsibility for supporting and mentoring those interactions and relationships (Davis, 2005; Gaither, 2008; Gathercole, 2007; Murphy, 2012; Ray, 2009). They believe that homeschooling 
provides the most appropriate milieu for teaching, modeling, and child-application of social mores and appropriate social behavior. Moral and/or religious concerns were not primary motivations at the inception of the modern homeschool movement in the 1960's (Murphy, 2012). As the public-school system became more secularized, the home school movement grew and by the 1980's the majority of parents who homeschooled did so because they wanted to instill their beliefs within their children (Cizek, 1993; Gaither, 2008; Kunzman, 2009; Murphy, 2012). "Repeatedly, motivation for most home educators reflects a moral, spiritual, or religious component" (Cizek, 1993, p. 1). According to Davis (2005), homeschooling provides an environment conducive to appropriate and meaningful peer relationships without the fear of bullying and violence that occurs in the public-school system. Davis contends that the close bond formed amongst family members and the opportunities for interactions with individuals of various ages provides an authentic experience that promotes personal growth.

The motivational forces that have united the parents of diverse ideological orientations parallels the attitudes regarding assessment of outcomes as individual families and as a larger group. While the public-school system emphasizes the need for quantitative standardized measurement of outcomes, homeschooling parents emphasize the more qualitative (and sometimes subjective) measures demonstrated through their children's attitudes toward learning, interest in social mores and social causes, involvement in community, church, and family activities, and pursuit of individual interests. They argue that, as involved parents, they know if their child is learning and do not need standardized tests or research to demonstrate that learning has occurred (Davis, 2005; Griffith, 1998). Former special education teacher, homeschool parent, and author, Davis (2005), states, "It is not necessary to use grades to decide whether or not a child has mastered a skill... mastery is obvious" (p. 129). Summarizing a homeschooling parent's words to Griffith (1998), when asked how a parent can tell that learning is occurring, she said, "through active involvement children tell what they are learning; but I have to think 
about it much in the same way that I think about their physical growth" (p.56). It is not something a parent sees on a daily basis, yet the cumulative effect can be viewed as the school year progresses. According to Rudner (1999), "Public and private schools usually select [a standardized test] ... due to its close alignment with their curriculum; home schools select the test primarily out of convenience" (p. 28). Rudner (1999) noted that homeschool families do not necessarily follow the same scope, sequence, or emphasis as traditional public and private schools.

Many parents maintain a deep conviction that individualism, creativity, cultural and personal values, and civic engagement, all believed to be integral to healthy development, could best be taught in a loving, supportive home environment (Davis, 2005; Gathercole, 2007; Griffith, 1998; Murphy, 2012; Ray, 2009). According to Green and Hoover-Dempsy (2007), “A parent's decision to homeschool is motivated not only by the parent's psychological beliefs but also by the parent's perception of contextual variables that influence the feasibility of homeschooling" (p. 272). Murphy (2012) states that an "essential law of social science is that context almost always matters" and that "nowhere is this conclusion more obvious than in the realm of homeschooling" (p. 80). Thus, it can be suggested that integral to a parent's desire, or motivation, to homeschool is a desire to provide opportunities for exploration in learning. These opportunities for exploration are cornerstones for the formation of identity.

Parental methodology. Parental motivation for homeschooling, parenting style and personality, children's learning style, and availability of resources are all considerations when choosing a curriculum and teaching method. Many families new to homeschooling may choose a more formal approach, opting for comprehensive curricula that includes scope, sequence, learning benchmarks, and assessments. Others may choose to "unschool" (Griffith, 1998) an approach rooted in the teaching of John Holt (1964), which emphasized the value of experiential 
learning in the course of daily living. Those who unschool their children do not typically follow a prescribed scope, sequence, or program.

Whatever the venue for learning (parents' home, homeschool co-op, or other), whatever the level of structure (from an 'unschooling' approach to a rigid schedule), whatever the curricula (a parent-selected 'mix and match' approach, school district texts and materials, 'canned' curriculum with lesson plan guides, cyber-school, or self-directed paces), there exists a common undeniable concern; a foundation for learning must consider the needs of the learner in the implementation of the educational program. Following is a brief description of the most commonly used curricula and/or methodology in what can be labeled as homeschool programming, although some involved in the process would disagree with the term 'program' (Gaither, 2010; Gathercole, 2007; Griffith, 1998; Murphy, 2012).

(a) Classical Education - An approach also known as the Socratic Method. Learning opportunities are built around the student's level of cognitive development. Lessons tend to be highly structured, yet there is room for flexibility, based on student need.

(b) Eclectic Education - An approach that employs a variety of curricula, ideas, and methodology, depending upon the subject and/or the student need. There may be a combination of parent-led instruction, on-line learning, and video.

(c) "Charlotte Mason" - An approach which generally uses short lessons facilitating focused attention. There is an emphasis on the child's natural learning. Variation is built into the daily schedule. Knowledge is demonstrated from narration and discussion rather than test-taking.

(d) Integrative Eclectic Education - An approach that integrates any of the first three approaches. Cognitive development and student interest are considered. Unit-type studies are often employed that focus on a topic which allows for cross-curricular 
integration. There is a high degree of structure in some areas and a lesser degree in others.

(e) Unschooling Education - Unschooling is perhaps the most challenging methodology to describe because the focus is on the child's innate learning abilities and interests. To a large degree, it is based upon John Holt's teaching that "living is learning and learning is living." There is no structured curriculum.

(f) Virtual (cyber) Education. An approach wherein all subject matter is delivered online. Students are generally enrolled through their local public school.

Perhaps even more variance is seen in the methodology used in homeschooling than in the motivations for doing so. Unquestionably, there are opportunities for individualization that can enhance development in all areas. Constructivism assumes that knowledge is attained through active interactions with the environment (Hala, 1997). Congruent with best practices from a constructivist's paradigm is the intentionality of homeschool parents to provide opportunities for their children to learn experientially which promotes the exploration necessary for identity formation (Davis, 2005; Gathercole, 2007; Ray, 2009).

Constructivist philosophy may not be cited directly as a theoretical foundation for homeschooling methodology, however many descriptions by parents of the process would most appropriately be classified as following a constructivist's model. Related closely and even subsumed within an instructional model is one's parenting style. Anecdotally from conversations with homeschool parents and in texts written by homeschool parents (Bauer \& Wise, 2009; Davis, 2005; Gathercole, 2007) it appears that authoritative parenting is the most frequently-cited parenting style of those who homeschool their children. Upon initial consideration, authoritative parenting and exploration as part of constructivist's philosophy may appear to be mutually exclusive but in the words of Wessling (2013) "Authoritative homeschoolers encourage their children to question the validity of what they are studying, argue, 
for changes in curriculum or approach, and lead their own studies when appropriate" (para. 5). Wessling further emphasizes the balance between freedom to learn and responsibility to learn. Research has shown that children and adolescents whose parents use authoritative parenting styles fare better in areas of competence, self-esteem, moral development, and autonomous functioning related to identity formation and that authoritative parenting is the parenting style most predictive of positive outcomes for adolescents (Holmbeck, Paikoff, \& Brooks-Gunn, 1995). Authoritative parenting was the only style to significantly foster an informationprocessing style in the adolescent (Berzonsky, 2004). In examining the methods used by homeschool parents, there is reasonable justification to posit a correlation between methodology and the exploration so necessary for the formation of identity.

Challenges in research. Research related to outcomes of homeschooling is extremely limited in scope. Specific outcomes related to academic achievement (e.g., individual excellence in various national competitions, SAT scores, college completion) are available yet there are no standardized measures available to assess overall average academic success of all homeschoolers as a collective group. Admittedly there is much to learn about the outcomes associated with homeschooling and a need for further research. There exists even less research related to the psychosocial development of those who receive their education in the home. Until there are more effective methods for obtaining reliable data, research regarding academic and psychosocial outcomes of students who are homeschooled, provides us only with suggestions and direction for future research. Numerous researchers (Gaither, 2008; Murphy, 2012; Ray, 2010; Reich, 2005) have addressed the paucity of research by elaborating on significant challenges in obtaining valid data.

Kunzman and Gaither (2013), who synthesized the existing research base related to homeschooling from over 1400 academic texts, point out the inherent limitations as a result of many of the aforementioned factors and thus warn against overgeneralization of some of the 
stated conclusions. Gaither (2008) further explains that the majority of books about homeschooling are written either by those with a vested interest in the process who use their work to advocate for homeschooling and/or to provide assistance to other homeschoolers, or by scholars whose approach is either, "to critique it or to understand it as one might wish to understand a foreign culture" (p. 1) in which case a paradigm shift is needed, one that would approach homeschooling outcome measures in the same manner that one examines outcomes associated with traditional education.

Brian Ray, a professional educator well-known for researching academic outcomes associated with homeschooling stated, "Homeschool people are very privacy-oriented, slow to give information to government entities" (2014, p. 2). Murphy (2012) elucidates the need for research on homeschooling by contrasting the lack of research on homeschooling to the wealth of research on charter schools, noting that charter schools developed approximately fifteen years later (1990 versus 1975) than the modern homeschooling movement (p. 13). Citing Kunzman (2009) and Ray (2011), Murphy (2013) further states, "Even when they agree to be counted, resistance on the part of some of the homeschool community to engage with researchers is legendary (p. 14).

Understanding the assessment and research paradigm associated with homeschooling can be enhanced through an analogy found in the discipline of alternative/naturopathic health. It is widely known that the practice of alternative medicine has grown substantially in this country in the last thirty years, yet many of the treatment modalities have little if any scientific evidence of efficacy. Those who benefit from these therapies and treatments attest to the success, yet there has been little research to support the claims. In much the same way, some parents of homeschooled children see no utility or need for standardized measures of success nor are they interested in associated research to simply demonstrate what they already believe. 
Relevant Research Studies. In the vast dearth of valid research, there exists a few reasonably controlled studies examining measures related to psychosocial development. They are qualified as reasonably controlled because there is no evidence of randomization and demographic information is incomplete. Having thus qualified, one such noteworthy study by Ray (2004), surveyed more than 7,300 adults who had been homeschooled as children and found several common characteristics among the respondents who had been homeschooled for seven years of more $(n=5,254)$, when compared to the general population: (a) college attendance was higher, (b) there were higher levels of community service and involvement in community organizations, (c) higher levels of civic engagement as evidenced by greater percentages of those who voted in the previous five years, attended public meetings and/or called public representatives, or became involved in or contributed to political campaigns. One obviously cannot presume cause and effect based on homeschooling yet grounded in Erikson's definition of identity achievement positing a link between exploration and commitment to self-selected values and organizations, there exists just cause for hypothesizing correlation.

Regarding the exploration necessary for identity formation, White, Moore, and Squires (2009) found that homeschooled students scored higher on a test of openness to experience than students who were traditionally schooled. Once again due to small sample size, the results must be considered cautiously. Gathercole (2007) maintained that the flexibility inherent in the homeschool schedule provides an adolescent with the freedom of ideological exploration and opportunities for community involvement and engagement. Davis (2005) postulates that it is not healthy for children to spend such an enormous amount of time as part of age-segregated groups (i.e. traditional educational settings), essentially expecting them to be socialized by one another. This sentiment correlates to one of the primary motivations of parents for homeschooling, the environmental concern related to appropriate socialization free of violence and bullying. 
Personal conversations with numerous home school advocates who support and promote socialization opportunities outside the home believe it is the parent's responsibility to provide open discussion with their adolescents in order to facilitate an adolescent's ability to make such choices.

In a survey by the Homeschool Alumni Research Organization (HARO, 2015) of 3,702 homeschooled alumni results showed that the former homeschoolers were reasonably engaged in society. However, the exact meaning of reasonably was not provided. Regarding the study's finding related to socialization; $73 \%$ of the respondents rated their socialization as average, good, or very good. There was a high correlation between perceived level of socialization and belief that homeschooling prepared them for the future. Cooperative learning experiences and participation in sports led to higher levels of socialization.

Smith and Sikkink's (1999) study of 9,300 homeschooled families, which controlled for differences in education income, age, race, family structure, geographical region, and the number of hours worked weekly by parents, suggested that families who homeschool their children or send them to religious-based schools, are consistently more involved in civic activities than families with children in public schools. The finding is noteworthy, in that according to Erikson (1968), adolescent civic engagement can be interpreted as one sign of ideological commitment related to identity achievement. However, one can reasonably speculate that similar results may be obtained when applying the same controls to families whose children attend public or private schools. Additional insight worthy of consideration, related to potential psychosocial outcomes is expressed in the views of adolescents experiencing the process.

Although lacking valid research methodology, Gathercole (2007) provides an intriguing insight through excerpts of interviews conducted with over two dozen homeschooled adolescents. Overwhelmingly the adolescents expressed freedom of thought and expression as a primary benefit of homeschooling. Many viewed the opportunities for exploration of their ideas 
and interests as the most significant factor related to their desire to be homeschooled. While void of valid research design, these sentiments are certainly worthy of consideration. Perhaps what so many adolescents appreciate in their homeschool education is exactly what has been identified as crucial to the formation of identity.

Extrapolations from theoretical constructs applicable to homeschooling. There is no shortage of research indicating the significance of socialization in the development of identity (Adams \& Marshall, 1996; Hogan \& Roberts, 2004; Reitz, Zimmermann, Hutteman, Specht \& Neyer, 2014; Swann, 1987). The disequilibrium inherent in the socialization process is part of the adolescent's necessary crisis of identity. Indeed, the function of socialization and the quest for individual identity are inextricably linked. Socialization facilitates the sense of belonging, connectedness and significance to others, while also providing the basis for commitment to personal values, beliefs, and goals. It is in fact the displays of loyalty and commitments to ideological institutions which mark the successful resolution of the identity crisis (Markstrom \& Marshall, 2007). For healthy resolution of this crisis it is imperative that adolescents are provided with an environment which fosters exploration, encourages questions, accepts resistance to status quo, stimulates critical thinking and also provides the boundaries necessary for the adolescent to make socially and emotionally healthy decisions. Homeschooling is an educational choice conducive to such an environment.

There have been several studies related to questions about socialization of those who are home schooled, however, most are bereft of empirical data to support the stated conclusions. Many are quasi-qualitative in nature, employing interviews and observations that while credible, cannot be considered as valid research due to the obvious biases of those reporting the data. Considering the research limitations previously stated, Kunzman and Gaither's (2013) comprehensive overview of the research on homeschooling provides an elucidation of the variables associated with demographics, curriculum, academic achievement, socialization, law, 
relationships with public schools, and transition to college/adulthood. Specific findings germane to adolescent identity formation can be extrapolated from their synthesis. Socialization entails not only how children interact with others in various social settings, but how children develop convictions about what is significant to them and why (Kunzman \& Gaither, 2013, p. 21)

Belfield (2004) pointed out that parents have stronger incentives to care for [in terms of educating] their children than does the state. Given the increasing number of bullying-related suicides and school violence, it is understandable that some parents conclude the home to be a more appropriate environment for growth, learning, and socialization. According to the National Center for Educational Statistics (2015), social concerns were the primary motivating factor parents cited for their decisions to homeschool. In a study (Vigilant, Trefethren, Anderson, 2013) of 21 homeschooling fathers, the common belief expressed relevant to socialization was that societal and educational institutions have failed to socialize children according to basic and ethical moral standards. The response to the perceived [cultural] failure is "an attempt to build the home and homeschool as an arena for total socialization... to be an institution of successful and consistent socialization into knowledge acumen and collective moral sentiment" (p. 218).

\section{Literature Review Summary}

Erik Erickson's $(1959,1968)$ model of psychosocial development provides a framework for further conceptualizing the potential facilitative role of homeschooling in the adolescent quest for identity. The opportunity exists for parents to provide the necessary psychosocial milieu conducive to successful resolution of the identity crisis. As previously noted, Adams and Marshall (1996) have asserted a parallel between the function of environmental factors in the process of socialization and the process of identity formation as described by Erikson (1968). Socialization in the context of homeschooling is unquestionably integral to the adolescent's development of convictions and choices regarding worthwhile commitments. Homeschooling parents maintain that healthy families provide optimal environments for providing socialization 
opportunities and fostering social development. Because mothers tend to provide the instruction in home education, it was appropriate to focus this study on mothers' perception.

While the practice of home education does not guarantee specific academic or psychosocial outcomes, parents are afforded the opportunity to provide an environment rich of support and understanding which are crucial to the development of self. The parent-child attachment and interaction that are inherent in the process of homeschooling can provide not only a productive learning environment but also lay the foundation of support which encourages critical thinking necessary to the formation of an individual identity. Marcia (1980) suggested that identity achievement resultant from high quality exploration could be predicted by a history of secure attachments between parent and child. Parents who homeschool their adolescents unquestionably have the potential of forming significant attachments with their children.

There is reasonable justification to suggest that homeschooling can provide the availability of parental support and open dialog critical to the process of identity formation. Additionally, opportunities abound for the provision of exploration that is foundational to the process. Home education can provide a safe environment for the necessary exploration which is an integral part of identity formation. Opportunities for adolescent exploration through parental engagement are present on a daily basis with just a little forethought and planning. Flexibility in scheduling produces numerous opportunities for community involvement. In an empiricallybased study, Smith and Sikkink (1999) found that homeschooling families are significantly more likely than public school families "to participate in public life through a broad range of activities" (p. 18). There exists a plethora of venues available for activities facilitating the process of adolescent exploration and personal growth necessary for identity formation.

Excellent possibilities for engagement with people and organizations in whom an adolescent can have faith are readily available in the process of home education. Integral in the homeschooling experience are opportunities for regular investigative field trips, participation in 
youth groups with specialized focus, meaningful self-selected apprenticeships, social and/or political activism, and community service and outreach, all of which can provide the basis for adolescent exploration enabling eventual commitment to self-selected values and beliefs. According to Erikson (1959) civic engagement is associated with identity achievement. As has been noted, studies have indicated high levels of civic engagement amongst homeschoolers. Empirical data related to homeschooling outcomes is limited at best, particularly those measures associated with psychosocial development. Thus, prudence must be exercised in evaluating both the criticisms and the testimonials of success. An on-going conversation encouraging openness between all stakeholders (i.e., parents, professional educators, researchers, legislators, and civic leaders) is desperately needed to adequately address the questions about how these young people are forming a sense of self that provides meaning, direction and purpose in life.

\section{Research Questions}

1. How do parents describe their motivations for engaging in homeschooling?

2. How do parents describe the methods used in homeschooling?

a. How might parental explanations of homeschooling methods align with adolescent identity theory? 


\section{Chapter 3: Methodology}

\section{Participants}

Participants were 26 mothers of homeschooled adolescents (i.e.., 15 through 18-year-olds in grades $9-12$ ) who live in Pennsylvania. The majority described themselves as Caucasian, two identified as mixed race, and one preferred not to answer. Educational levels of the mothers in the study were predominately four-year college degrees. Four had a master's degree, two parents obtained their high school degrees or equivalency, and the rest had a bachelor's degree. Regarding the academic levels of the adolescents, two mothers noted that their children had special learning needs when they began homeschooling, while four others stated that their children required more intense academic rigor than what they believed to be available in the public school system.

All but two mothers described their method of homeschooling as incorporating some degree of structure; one identified a method with very little structure, and one parent identified a highly structured program. The questionnaires provided a delineation between structure and methodology, yet the mother's responses demonstrated an interchangeable use of the terms. It appeared that the terms were interpreted as synonymous.

Purposive sampling was used because of the well-documented difficulty in obtaining a randomized sample of homeschoolers as explained in Chapter Two. Purposive sampling is used when focusing on particular characteristics of a sample; it allows for generalizations to be made about the given sample. Participants who represented the diversity of homeschooling methodologies and reasons (motivation) for homeschooling were sought. This was accomplished through an online search for homeschool support groups and co-operative learning networks representative of diverse ideological, pedagogical, and religious homeschool orientations. The managers of 48 listservs were contacted for permission to post a brief description of the study and an invitation for listserv subscribers to participate (Appendix B). 
Those interested in participating in the study could access it through a link to the Qualtrics

Research Platform (Qualtrics, 2017). Additionally, the same invitation to participate was posted on social media with the same link to Qualtrics. Using home school support group directories from across the state, it was assumed that contact could be made with a large majority of the home school support groups.

In addition to having experience with homeschooling, participants also needed to have adolescent children between the ages of $15-18$. This age range was chosen because it represents the time during which the greatest level of identity exploration occurs (Erikson, 1968). Additional rationale for limiting this study to that age range is that logic skills such as probabilistic reasoning and hypothetical reasoning, necessary for the formation of identity, are not operational until middle adolescence (Kroger, 2007). Older adolescents who were previously homeschooled were also not included.

\section{Procedure}

After IRB approval (Protocol \# 1803018707) for the study was granted, over 200 home school support group coordinators from across the state of Pennsylvania were contacted via email with a request (Appendix C) that the invitation to participate in the research study be forwarded to their group members. A second invitation/reminder was sent to the coordinators one week later. A total of nine coordinators responded affirmatively. An invitation to participate in the study was also placed on Facebook, with numerous acquaintances sharing the information. After an additional two weeks with very limited responses, the researcher personally contacted acquaintances who homeschool and requested that they provide the URL for the study to the coordinator of their respective home school co-ops.

Upon opening the link to Qualtrics, the following documents were made available in the order listed. First, an introduction to and instructions for participation in the study were presented (Appendix D), which explained the purpose of the study and provided detailed instructions for 
progressing through the study. A series of demographics questions (Appendix E) asking participants about family size, parent educational level, children's age, and others, were asked. Next, a series of five open-ended questions were asked that provided insight about participants' homeschooling experiences (Appendix F). For example, they were asked to "Tell me about your motivation for homeschooling your adolescent" and "In what ways do you believe that the homeschooling experience influences and/or impacts your child's maturation as a unique individual?"). Then, participants were asked to respond to a forced-choice ranking of their reasons for homeschooling (Appendix G). Participants then were provided descriptions of the most commonly utilized methods in homeschooling and were asked to identify the degree of structure in their own homeschool program (Appendix H). Finally, participants were provided descriptions of commonly used curricula and asked to identify the one that most closely describes their own homeschool program (Appendix I).

The documents were linked in such a way that each one opened successively only upon completion of the previous document. Prior to participation, participants were told that their personal information would remain confidential.

\section{Analysis}

Strauss and Corbin (1990) defined qualitative research as research about "people's lives, stories, and behavior, but also about organization functioning, social movements, or interactional relationships" (p. 17). Existential investigation facilitates the quintessential understanding of the very essence of and process used in homeschooling.

Analysis of the data was guided by an interpretive paradigm that integrated the essential elements of the homeschooling experience and the theoretical understanding of the process of adolescent identity formation. Marcia's (1993) conceptualization of Erikson's (1968) theory of identity formation provided a context for understanding how the parents' motivations and methodologies in homeschooling can support identity formation. 
Thematic analysis has been used to identify, analyze and report patterns (themes) within data. It assists the organization of data and provides an in-depth description of the data set. Braun and Clarke (2006) described thematic analysis as a foundational method in qualitative analysis providing theoretical freedom and flexibility while also providing detailed and complex accounts of data. Thematic analysis was an excellent choice for this study because it could be used within differing theoretical frameworks. This is significant in that the review of literature includes constructs relevant to identity formation from several theoretical models. An additional benefit of thematic analysis is that it can follow essentialist or constructionist methodology (Braun \& Clarke, 2006). Given the broad ranging philosophical orientations and methodologies used by parents in homeschooling, thematic analysis is a logical choice in explaining the meaning of the qualitative data.

Consistent with thematic analysis the researcher intentionally attempted to unravel and explain the homeschool experience in the context of the parent-adolescent experience through the following open-ended questions (Appendix F): (1) Tell me about your motivation for homeschooling your adolescent. (2) Why do you continue to homeschool? (3) Please describe the degree of structure in your homeschooling experience. (4) How are your motivation for homeschooling and the structure (or methods) you use related? (5) In what ways do you believe that the homeschooling experience influences and/or impacts your child's maturation as a unique individual? Each of the questions align with the overarching research questions as stated at the end of Chapter Two.

The parents' responses to the open-ended questions (Appendix F) were analyzed and coded. The 26 parent responses were then exported from Qualtrics into a Word document, organized by each individual question. After the first reading, a list was made of frequently occurring words or phrases in the responses. The five questions were analyzed one at a time. A second reading was done to confirm that all frequently occurring words or phrases had been 
identified. The list of frequently occurring responses for each question was then categorized. The first two questions examined parent motivation for homeschooling. An example of the categorization and coding for these questions was the identification of one of the major categories of motivational factors to homeschool; a category titled "environmental" was identified as were subthemes within the broader categories. For example, a concern for safety was identified as a subtheme of the environmental motivation to homeschool. After categorizing the list of responses, the responses were read again, highlighting each frequently occurring response according to its category. Motivations related to academic concerns were highlighted in one color, those related to environmental concerns were highlighted with another color, and those related to spiritual/moral concerns were highlighted with a third color. After highlighting the responses, the number of responses in each category was counted to determine the most salient motivation for homeschooling among the parent participants. A fourth reading was done to ensure authenticity with the categorization and to identify any unique responses. The same process of coding was used for all questions.

Information from the open-ended responses was supplemented by parent responses to the following: (a) Parental Information - Demographics form (Appendix E), (b) Parental Motivation form (Appendix G), and Homeschooling Methodology form (Appendix H). Parent responses on each of these forms assisted with analysis and categorization of motivation and methodology.

The trustworthiness of the development, execution, and analysis of the study was established and maintained using member checks. Two homeschooling mothers, both having bachelor's degrees and combined homeschooling experience of 22 years, well-known by the researcher, were consulted during the development of the questions for the survey. Both mothers had previously homeschooled adolescent children and both were currently homeschooling one adolescent. In reviewing the open-ended questions, the mothers provided valuable feedback regarding clarity and utility of the questions. Upon completion of the surveys by the twenty-six 
respondents, one of the mothers categorized the responses to the $1^{\text {st }}$ and $2^{\text {nd }}$ open-end questions regarding motivation for homeschooling. Her categorization was checked with that of the researcher. There was a $96 \%$ agreement (50 of the 52 responses). In the two instances of disagreement, the researcher had identified the motivation of two mothers as falling into two of the three categories whereas the mother who was serving as a member-checker, believed the responses indicated that the motivations related to all three categories. After discussion with the mother, coding of the responses was changed to indicate motivations in all three categories. 


\section{Chapter 4: Results}

The purpose of this study was to examine the potential facilitative effect of homeschooling in the identity formation of adolescents as perceived by the mothers who homeschool. The analysis of data is described in this chapter. Thematic analysis was used to identify the following themes.

\section{Parent Motivation to Homeschool}

Mothers' motivations for homeschooling revolved around three distinct rationales: academic concerns, environmental concerns, and moral/religious concerns. Academic and environmental motivations were ranked equally as motivating factors. Spiritual and/or more motivations were more often identified in combination with one or both other motivating factors, rather than as a sole motivator. Each of these motivational factors are discussed separately.

Motivation related to academic concerns. A common thread found in mothers' responses in this study regarding motivation for homeschooling was the desire to provide a quality academic education. Mother 21 commented, "Our son is thriving in his current environment scholarly and chooses not to go back to public school." This mother seemed to view an appropriate and positive learning environment to be intrinsic to a quality academic education. Some mothers viewed the completion of homework, which they described as unnecessary for mastery of content, as well as the completion of chapter and/or unit tests as meaningless and a waste of time. Mother 17 commented that, "Homework is what is completed every day during the day." Mothers said their children did activities such as mapping routes for trips, writing summaries of various careers available in healthcare, integrating math, social studies and language into reports and presentations at a home school coop, and designing spaces for flower gardens as a culminating project for a unit in Geometry. 
The most frequently occurring theme associated with academic motivation for homeschooling was the opportunity for individualization. Mother 4 succinctly stated, "We want to provide our children with an individualized education that meets their individual needs and interests and provides time for them to pursue their own interests." This concern was voiced by mothers whose children had diagnosed learning disabilities, were considered gifted, and/or wanted the freedom to explore areas of individual interest. Mother 15 identified motivation for homeschooling by a desire to, "instill a love of learning by emphasizing strengths and supporting individual weaknesses." The mother (16) of a child with special learning needs stated, "At first we started to homeschool because our daughter had learning challenges but then it changed so we could tailor each child's education to best prepare them for adulthood." Without question, these mothers reported believing that significant opportunities existed in the homeschooling milieu for individualization in all areas of the teaching/learning process.

A related theme that emerged from the data relevant to academic concerns was a desire for an increased level of intensity in learning. That desire was expressed by Mother 8 who said: "We changed from the curriculum the school was using to a more intense program." Mother 19 said that a "lack of rigorous academics at the local public school" was a motivation for homeschooling. Mothers voiced the belief that meaningful learning occurred because they had the opportunity to support their adolescents' individual interest in specific topics. For example, one mother mentioned that homeschooling allowed her adolescent the extra time needed to excel in writing, reading, speech, and history that public school did not. More broadly, Mother 4 noted, "We want to provide our children with an individualized education that meets their particular needs and interests and provides time for them to pursue their own interests." Another example was a student who was more interested in the causes of the Civil War than in the causes of the Revolutionary War. Mother 25 stated, 
There's a lot more controversy about the causes of the Civil War than with the Revolutionary War. The Civil War has been so politicized that you have to dig deep to get the whole picture. My daughter was very interested, so we turned it into her major project for the year, with field trips, a report, a presentation at our coop, and a mock debate.

Mother 25 felt that both were important for the adolescent to learn yet believed that the opportunity to adjust the time spent on each topic helped promote an increased interest and engagement in learning.

Academic concerns related to assessment. Standardized testing was an underlying concern that plagued some mothers and can negatively impact parents' willingness to participate in any associated activity, particularly research studies. In Pennsylvania, homeschooled students are required to participate in standardized testing. In the words of Mother 26, interviewed informally by this researcher,

I abide by the law and take my kids for the required testing, but you and I both know that those standardized tests reveal very little about real learning. I get nervous every year we go until we get the results, because unlike public school, we do not teach to the test. We enjoy learning and too much emphasis on testing would destroy the fun in learning.

The concern and thoughts about testing were summarized by Mother 9,

She has already had more experiences than $99 \%$ or more of public-school students, because they generally have to teach to the lowest common denominator. With homeschooling, we have the ability to teach to the individual's capability and interests, rather than teaching to a test.

Parental resources and beliefs are integral to decisions about what subjects are taught at a particular time. The parents' educational levels, financial situation, and number of children are also important considerations. For example, the majority of public schools in Pennsylvania teach 
Civics in $8^{\text {th }}$ grade, which also happens to be one of the state-mandated grades for standardized testing. If a homeschool family has children in $7^{\text {th }}$ grade and $8^{\text {th }}$ grade, they may consider it a better use of resources to teach it once to both children and wait until the following year when the younger student is in $8^{\text {th }}$ grade. Such a decision could however cause the $8^{\text {th }}$ grade student to score low on the standardized achievement test for that academic year. Thus, the flexibility in curriculum and structure that homeschooling families cite as one of the many benefits of homeschooling can lead to misinterpretation of academic success if not viewed in context.

Motivation related to environmental concerns. Environmental and academic concerns were ranked as equally important according to parents. The principal theme that emerged relevant to environmental concerns was related to safety, which included the provision of a socially-appropriate environment free from bullying.

Mothers expressed the desire for their adolescent children to have healthy, positive relationships devoid of negative peer pressure and bullying. Mother 13 remarked, "We started homeschooling to provide a healthier and safer environment for our kids. Our eldest child dealt with bullying and other school frustrations. He likes the freedom of schedule and does not want to go back to public school." Mother 21 stated, "Our son was being bullied in school and having social struggles. We also had difficulties with teachers bullying him." Some were concerned for the level of school violence, even if their children were not the victims of bullying. Some mothers took a proactive stance because of violence at other schools, like Mother 7 who said: "We saw the dangers in the public school rising as I was pregnant with our first child when the Columbine shooting happened." Commenting on the relationship between identity development and a safe environment, Mother 17 said,

While being away from the daily influence of the public-school structure and drama, my child has been able to search out his own personality, struggle through his identity in the 
safety of his own family interacting with siblings and parents, as well as other adult and youth community members.

Speaking in general terms about safety concerns, Mother 14 said, "We homeschool so our children will have a safe environment and because it is working for us and the world is just getting worse." The provision of a safe, healthy environment for learning was a significant motivational factor for many mothers.

Motivation related to moral and/or religious concerns. As with environmental and academic motivations, there emerged themes within the responses related to moral/religious motivations. The most commonly-occurring theme was the opportunity to integrate spiritual principles with academics. In cases where moral/religious reasons were cited concurrently with academic and/or environmental reasons, all three were counted as primary motivating factors. Mother 16 remarked, "We realized it wasn't just about academics, but about their spiritual, physical, and mental growth as well. Public school cannot meet the needs of an individual's growth like homeschooling can." Mother 17 said, "We continue to homeschool to provide individualized instruction, opportunity for religious instruction, and to avoid the drama and peer pressure of the public-school atmosphere." It appeared that these parents use an integrative approach in religious education, rather than presenting it as a separate part of the overall curriculum.

Six of the mothers I spoke with believed that peer relationships are important to healthy adolescent development, but also believed that unhealthy or negative peer interactions could impede development. Mother 23 elaborated, "We are not trying to shield our son from exposure to different values and beliefs. Actually, we want to expose him to different values, beliefs, and people, but in a setting where we can help him process what he is seeing and experiencing." Mother 24 of one of the students in the coop said that her husband teaches an Apologetics course for the coop students because, "We want them to know why they believe what they do and have 
freedom to question it. They can't get that in public school." Mother 26 expanded on opportunity to question in saying,

Our nieces and nephews in public school are being taught to question Judeo-Christian values but are being silenced if they question secular or other religion's beliefs. We want our kids to be exposed to a wide range of beliefs but also know why we believe what we do. Ultimately, their beliefs are their decisions, but right now, it's our job to teach them what we believe to be true.

"We want to provide a quality education with a Christian worldview," was stated by Mother 9 as motivation for homeschooling. Only two of the 11 mothers who identified religious/moral issues as a primary motivation identified it as the single primary motivating factor, with Mother 10 saying simply, "A Christ-centered education is best." Mother 1 stated, "For conservative/Christian content and character development." Homeschooling provided an opportunity for parents to integrate their values and beliefs into all curricular areas.

Religious and/or moral motivations were more often identified in combination with one of the other motivational factors than as the only motivational factor. Mother 12 stated her motivation in general terms, "Our motivation is a lifestyle choice for their spiritual, mental and emotional well-being." Mother 14 stated, "We choose to do it because we want our children to have a classical Catholic education in a safe environment, away from the pressures of school." Some parents in the study articulated a holistic view of the learning process in that they combined environmental, religious, and/or academic concerns as their motivation for homeschooling. In combining environmental and academic concerns, Mother 5 said, "There is more time available for parents who homeschool to be the major influencers and role models in their children's lives." Mother 9 stated, "We do it [homeschool] for the quality of education, for a Christian worldview, and for safety from bullying and other violence." Mother 6 stated, "We do it for a higher quality education for a gifted student and for social concerns and safety 
concerns." Mother 3 summarized the benefit of the homeschool environment by saying, "They can be themselves and not worry so much about what the others think. They do not have as much negative peer pressure." Mother 12 stated, "Our current motivation is a lifestyle choice for their spiritual, mental, and emotional well-being." Mother 14 remarked, "My son is far more content with himself because he doesn't have to deal with all the pressures of outside school [meaning public school]. He thanks me frequently for not making him go to school.”

Reactive motivational factors. A minor theme that emerged in three responses was related to parents' prior educational experiences. Mother 2 remarked, “The dangers in public school plus the questionable things I was taught and decisions made in my public schooling made us choose to homeschool." Mother 7 was subject-specific regarding personal prior educational experience,

My husband, though successful in Math (98\% in Calculus for the year), struggled in writing, reading, speech, history, etc. and was just pushed through the private school he attended. We feared the same for our children when we saw some of them being exceptional in Math.

A personally positive prior homeschooling experience was cited by some parents as a rationale for homeschooling their children. Mother 11 remarked, "I have many reasons for why I homeschool my children, but I was homeschooled from 6th to 12th grades, and I loved the experience."

As can be seen from the following chart, the number of mothers who identified academic concerns as a primary motivation for homeschooling was equal to the number who identified environmental concerns as primary motivation. There are 52 responses because each mother identified both an initial motivation and a motivation for continuing to homeschool. In all 26 cases, the motivation to continue either stayed the same as the initial motivation or included one of the other motivational factors as secondary. 
Table 1

Motivations for homeschooling

\begin{tabular}{l|c|c|c|c|c|c|c}
\hline & Acad. & Enviro. & $\begin{array}{l}\text { Acad. \& } \\
\text { Enviro. }\end{array}$ & Rel./Moral & $\begin{array}{l}\text { Acad., } \\
\text { Enviro., } \\
\text { R/M }\end{array}$ & $\begin{array}{l}\text { Enviro. } \\
\text { \& R/M }\end{array}$ & $\begin{array}{l}\text { Acad. \& } \\
\text { R/M }\end{array}$ \\
\hline $\begin{array}{l}\text { \# of } \\
\text { responses }\end{array}$ & 10 & 10 & 7 & 4 & 15 & 5 & 1 \\
\hline
\end{tabular}

\section{Homeschooling Methods and Adolescent Identity Formation}

Methodology used by mothers in the study was identified through their completion of fixed-choice descriptions of the most commonly used methods in homeschooling (Appendix H). Those choices, as described by Bauer and Wise (2009) Davis (2005), and Murphy (2012) were as follows:

1. Classical Education

2. Eclectic Education

3. "Charlotte Mason"

4. Integrative Eclectic Education

5. Unschooling Education

6. Virtual (cyber) Education.

To further explore the participants' homeschooling experience as potentially foundational to adolescent identity formation, the mothers were asked the following questions relative to the methods used and the degree of structure employed (Appendix F): (1) Please describe the degree of structure in your homeschooling experience. (2) How are your motivation for homeschooling and the structure (methods) you use related? (3) In what ways do you believe that the homeschooling experience influences and/or impacts your child's maturation as a unique individual? 
Similar and overlapping thoughts were expressed in parent responses to the first two questions regarding structure and methodology. Unquestionably, the over-arching themes related to methodology were the opportunities for experiential learning and individualization in an environment conducive to learning. Another minor theme that emerged was the mothers' perception of an elevated level of maturation in the adolescent.

Structure and methodology. Several mothers articulated a desire to instill a love for learning while simultaneously providing structure and promoting independence. This was described by Mother 6 as, "mostly structured for a high school student, but also lots of freedom on book and curriculum choices. Project-based learning gives structure, freedom/independence on related topics." Mother 7 explained how structure (or methods) and independence complement one another, "We have a lot of structure because the kids asked for it. In high school we build on favorite electives and try others like cake decorating, industrial arts, sign language, graphic design, etc." The desire to provide guidance and structure while encouraging exploration was seen in the words of Mother 20, "It is structured but follows personal interest." Parent 20 described the balance of structure and independence by "try[ing] to keep a balance between her interests and what she needs to learn," while Mother 13 said, "I want our kids to be motivated independent learners... but give our kids flexibility and mentoring.” Mother 22 echoed similar sentiments in saying, "She interacts with others of various ages through her volunteering. She has time to pursue her own interests. There is structure in the mornings to allow for freedom in the afternoons for exploration of individual interests." Adolescents' interests, engagement in the learning process, and individual learning needs were the primary determinants of the degree of structure provide by parents. Some mothers who identified a high degree of structure also described their adolescent's freedom to choose depth of subject matter, electives, and activities as a benefit of homeschooling. Mother 16 stated, "Homeschooling has 
given our children more options for pursuing their interests without being locked into the school schedule."

Regarding structure, Mother 25 remarked that their homeschool experience is, "very structured in Math, somewhat structured in English, loosely structured in other subjects." Mother 10 commented, "loose structure with textbooks." "Fairly structured...choosing classes individually instead of a package deal," is how Mother 12 described their structure and curriculum. Mothers who design a long-range plan for their adolescent's high school experience appear to maintain a certain level of flexibility within their structure and curriculum. The scope, sequence, breadth, and depth tend to have significant variability across and within families. Many families belong to cooperative learning groups in which parents with knowledge and/or experience in varying subject areas take responsibility for specific subject areas. The scope and sequence are often determined by the availability of subject-matter experts. All of the mothers indicated that their adolescents participate in home school coops once a week. The coops are viewed by the mothers as a venue for appropriate peer interactions that play a part in their adolescents' socialization.

Individualization, experiential learning, and maturation. Identifying ways that the homeschooling experience influences and/or impacts a child's maturation as a unique individual, Mother 12 responded,

We believe that students learn everywhere. As we stand to their side, we attempt to filter vast amounts of information and influences surrounding them. We believe that if we stay in relationship with our kids, help build mentorships for them and gently guide their natural exploration of life - they will find the answers they seek. Answers to who they are as unique individuals, as well as answers to who they are in all of life.

Experiential learning combined with parental support are crucial in the process of identity formation. Addressing growth as a unique individual, Mother 20 noted, 
She has had the space to shape and understand her individuality with little peer pressure. She appreciates being unique and understands that everyone has the possibility to be unique as well. Having the opportunity to experiment and pursue her interests allows her to set goals and expectations with relatively low stress.

The significance of experiential learning and natural consequences was noted by Mother 18, "She has the opportunity to make choices and to experience the consequences (good or bad) of those choices while she is still under my guidance." The flexibility inherent in the process of homeschooling enables adolescents to explore areas of personal interests. Individuality and maturation were addressed by Mother 6 as,

She gets more rest and the time she used to spend on homework, she uses to interact with family and friends. The additional exposure she has to the world and all of its possibilities provide her with the experience necessary for maturation. She is more invested in our family and the community. She trusts and feels trusted which has greatly improved her confidence.

Several mothers identified elevated levels of maturation as a benefit of homeschooling. Some parents believed there was a correlation between elevated levels of maturation attributed to their adolescents by others with the opportunities afforded their adolescents to spend time with family, friends, and other individuals of varying ages. Mother 2 stated, "Many, many people we meet assume our child is much older than he is, and frequently comment of his maturity." Mother 19 said, "It was clear during interviews for college and college acceptance days that our child was way more mature than her peers accepted at the same college." The belief in the adolescent's maturity in relationship to engagement with others was evidenced in Mother 8's words,

With her varied interests, she spends time with people of all ages and interests. She is able to learn about things that she wants to know from people who know what they are 
talking about. She is comfortable with everyone from the farmer's infant to her 95 yearold grandmother, and can converse intelligently on books, engines, cows, cooking, sewing, raising beans, and a host of other subjects with anyone who is interested. She is constantly looking for new things to learn. I believe if she had remained in school, her interests would be narrow, and she would not be comfortable with people of all ages. Adolescents in the study participated in a plethora of activities in arts, sciences, and civic experiences (See Appendix $\mathbf{J}$ for a list of activities). Through these engagements, there were opportunities for interaction with same-age peers as well as individuals of different ages. The responses of several parents indicated a belief that the structure and method of homeschooling provided opportunities for growth and exploration of personal interests that would not be available otherwise as a result of time constraints inherent in traditional education. Mother 22 noted,

She has more chances to explore what she wants to do for a career. She really enjoys her work volunteering at the hospital. She didn't enjoy helping at the library very much. She likes helping with the younger kids at church. She helped in an auto repair shop once a week for a semester. She learned valuable life skills but knows she doesn't want to be a mechanic or bookkeeper. We couldn't have time for her to fit these things in (in addition to all of the other activities listed) if she was in school.

The homeschooling environment provides an opportunity for parents to see and experience who their adolescents are becoming on a daily basis. They are available to support them as they explore their interests and abilities. "I think that homeschooled adolescents are able to develop their own personalities and identities in a safe setting, without the worry of fitting in or being popular," stated Mother 26 in the study. Several mothers described the adolescent's freedom to choose depth of subject matter, electives, and activities. Mother 13 stated, "Homeschooling has 
given our children more options for pursuing their interests without being locked into the school schedule."

Responses of mothers in the study indicated a belief that their adolescents are being prepared for the future through varied, positive experiences in the present. Mother 17 stated, While being away from the daily influence of the public-school structure and drama my child has been able to search out his own personality, struggle through his identity in the safety of his own family interacting with siblings and parents as well as other adult and youth community members.

The mothers in this study employed a variety of methodological approaches with varying degrees of structure. There was a provision of support and guidance simultaneous with encouragement for adolescent exploration.

There did not appear to be a correlation between the methods used (as identified by the fixed-choice responses) and the degree of structure employed. Two mothers who identified direct instruction methodology articulated a low degree of structure. While at first glance this could appear as contradictory, it was congruent with their motivation for homeschooling. These mothers stated a desire for their adolescents to have the opportunity to explore areas of personal interests, yet believed that as facilitators in the process, it was their responsibility to provide direct instruction in some of their adolescents' individualized pursuits. Three mothers who identified an eclectic methodology said that they employed a high degree of structure. It appeared that those mothers believed that an eclectic approach provided opportunities for greater individualization, yet in order to complete work in all subject areas it was necessary to employ a high degree of structure. Mother 4 stated, "It is structured but follows personal interests." Mother 8 addressed the variance in structure based upon subject area, "We have a lot of structure in our schooling because the kids asked for it...in high school we build on favorite electives." Similarly, Mother 9 described their program as, "very structured in Math, somewhat structured in 
English, loosely structured in other subjects." The recurring theme that emerged from the mothers' descriptions of methodology and level of structure was individualization. The level of structure and the methods used were determined by the mothers' perceptions of their adolescent's educational needs. The following chart summarizes the mother's responses to degree of structure and methodology. An eclectic model was the most commonly employed method used by the mothers in this study. This appeared to be congruent with the frequentlystated desire for individualization and provision of opportunities for exploration in areas of personal interest. The vast majority of mothers described either a generally structured program or a program structured in most areas with less structure in other areas. Again, this was congruent with the desire to provide an education tailored to meet individual needs.

Table 2

Parental methodology

\begin{tabular}{|c|c|c|c|}
\hline Methodology & & Degree of Structure & \\
\hline Classical & 4 & Unstructured & 0 \\
\hline Eclectic & 7 & Mostly Unstructured & 1 \\
\hline $\begin{array}{l}\text { Charlotte } \\
\text { Mason }\end{array}$ & 3 & $\begin{array}{l}\text { Somewhat Unstructured with } \\
\text { structure as needed }\end{array}$ & 3 \\
\hline $\begin{array}{l}\text { Integrative } \\
\text { Eclectic }\end{array}$ & 6 & $\begin{array}{l}\text { Structured in most areas, } \\
\text { somewhat unstructured in others }\end{array}$ & 8 \\
\hline Unschooling & 0 & Generally structured & 9 \\
\hline $\begin{array}{l}\text { Cyber } \\
\text { Schooling }\end{array}$ & 1 & Very Structured & 2 \\
\hline
\end{tabular}

Note: Not all mothers responded to the questions regarding methodology and/or degree of structure.

\section{Recruitment Challenges}

Although not a specific focus on the study, it seemed important to note the difficulties the author had with recruitment seemed to be characteristic of the insular, and sometimes secretive, nature of many who homeschool. Conversations with homeschooling parents and representatives of home school support organizations revealed the primary reasons for a 
generalized reticence to participate in formal research were centered around various facets of assessment.

Mother 17 commented that, on more than one occasion, presenters at home school conferences admonished the attendees to "provide no more information to school districts or educational establishments than what is legally mandated." The same ideology is evident in online forums. The researcher was granted permission to join an "unschooling" list serve group but was not permitted to invite members to participate in the research study. Multiple times over the last 12 months, members on the list serve were admonished by other members to, "Tell them [school district personnel] nothing more than what they need to know." Comments such as, "Don't provide any information that can be used against you" and "Remember, we don't have to prove anything to anyone" are commonplace in the threads. This seemed to impact the willingness of parents to want to participate in this study.

The same sentiment was also seen in two of the largest home school networks in Pennsylvania: Christian Homeschool Association of Pennsylvania (CHAP) and Pennsylvania Homeschool Association. CHAP holds a yearly conference where many vendors advertise their products and services. The researcher believed the CHAP conference would provide an appropriate venue to solicit study participants. However, the request to provide a booth and/or disseminate information about the study was denied. In a phone conversation with a CHAP representative, the researcher was told, "We have a policy against providing support for specific research projects. You are free to use our online directory of support groups to contact individual coordinators." A former personal relationship with the founders/directors of the Pennsylvania Homeschool Association was the basis for soliciting cooperation from that organization in disseminating information about the research study. Two emails to them both went unanswered. 
Four mothers contacted the researcher and completed the open-ended questions, demographic information, and methodology questionnaire from the Qualtrics survey via phone or in-person conversations. Those conversations, as well as conversations with parents of adolescents in a home school co-op, have provided further insight into a conceptual paradigm held by some families who homeschool. Some mothers remarked to the researcher that their early years of homeschooling were fraught with uncertainty on a day-by-day basis regarding their children's overall progress. The mothers acknowledged increased confidence with increased experience. Mother 24 remarked, "Early on it was easy to see progress in the basics like reading and math, but more difficult to measure progress in other areas." She further explained, "The individualized approach makes it easy to determine if progress is being made." Mother 25, who had previously taught in public school, remarked, "In terms of getting things set up, structure, curriculum, scheduling, and such, it's not that different from a regular classroom. The more you do it, the easier it becomes." Lack of confidence seemed to impact potential participants, who thought their participation in a research study was like an evaluation of their performance.

The individuation inherent through home education is frequently cited by mothers as a strength of homeschooling, yet as can be seen from the previous examples, the individuation and flexibility can be potential weakness when addressing required standardized testing for their children. Conversations with homeschooling parents demonstrate a sincere belief that comprehensive and cumulative progress is best measured through maturation in knowledge as evidenced by interest in and participation in diverse activities. Mother 13 remarked, "I want our kids to be motivated independent learners, love God and others, be connected with family, be emotionally secure, and be prepared for life on their own." Mother 4 said, "We want our kids to have what they need to be successful in life, so we carefully choose materials for each child 
according to their needs, abilities, and learning style." Addressing the benefit of third-party assessment, Mother 25 said,

Sometimes we get so busy with every-day life that we simply don't think about our yearly goals until we get close to the end of the year evaluation. I used to get nervous about them but now I actually see it as helpful because it provides documentation of our kids' progress.

There are many complicated issues and dynamics associated with assessment in traditional educational venues where there is generally some degree of alignment between instruction and assessment. With the high probability of misalignment between instruction and standardized assessment in homeschooling, it is understandable that some mothers avoid participation in assessment and/or data-driven research. 


\section{Chapter 5: Discussion}

This chapter presents the summary and conclusions of the study. As the incidence of homeschooling has increased, the research of outcomes associated with the process has also increased. While the majority of research has focused on academic outcomes, well-documenting that homeschooled students consistently rank at or above national averages on standardized tests (Murphy, 2012; Ray, 2010), there is a dearth in research related to psychosocial outcomes. The primary intent of this study was to examine the potential facilitative effect of homeschooling upon adolescent identity formation. The goal was to identify mothers' motivations and methodologies that may provide a foundation for the exploration that is integral to the formation of an individual identity. The significance of this study in the context of Erikson's theory of psychosocial development is discussed. Finally, recommendations for further research conclude the chapter.

Families make the decision to homeschool for both proactive and reactive reasons. Some parents homeschool for primarily positive reasons; they want to provide academic, environmental, and or spiritual/moral advantages over what they believe their child would receive in public school. Others choose to homeschool to avoid perceived problems, including but not limited to perceived dangers, documented sub-par academics and/or perceived or real differences in values that are modeled or taught. Numerous studies (Green \& Hoover-Dempsy, 2007; Kunzman, 2012; Lines, 2000; Ray, 2009; VanGalen, 1991) about parental motivations have documented that regardless of primary motivational factors, parents who homeschool believe their children's education is their right and responsibility, and they do not want to give that authority to the school, which is echoed by the mothers in this study. Each of the primary motivational factors can provide a foundation that facilitates the formation of identity as the homeschooled adolescents seem to be encouraged and supported in their endeavors to explore 
and experience their individual beliefs, values, and interests based on what the mother participants report.

\section{Mothers' Motivation to Homeschool and Adolescent Identity Formation}

Erikson (1968) identified a stable, secure environment as foundational to the formation of identity and stressed the significance of allowing adolescents the freedom to make choices in their pursuits of ideas and institutions with which they will eventually commit. A common theme that emerged in the responses of mothers about their motivation for homeschooling reveals the desire to provide support for exploration. Mother responses reveal intentionality in creating and maintaining active, engaging learning environments. Numerous mothers expressed the desire to develop and maintain a safe environment where their adolescents would have the freedom to explore their own interests, and that the ideal environment for this to occur is via homeschooling. Unquestionably, the opportunities for exploration of personal ideas and interests are crucial in the process of developing an individual identity (Erikson, 1968). The level of support and engagement naturally varies from one family to another, but it reasonable to postulate that homeschooling, at least among this sample of parents, can be the epitome of parental support and engagement.

The mothers reported being intentional in exposing their adolescents to ideas, beliefs, and values that differ from their own. The mothers interviewed perceived that what they were doing was what was best for their adolescents to develop individual identities. Parents who homeschool often say that it is more appropriate for their adolescents to interact with peers and socialize in a controlled setting, void of negative peer influences, yet some would ask how such adolescents learn to deal with conflict. Rob Reich (2005), a political scientist who is one of the strongest voices in opposition to homeschooling, posits that the optimal venue for teaching and learning the values of "decency, civility, and respect" is the public-school classroom. He has suggested that students who are homeschooled lack the benefit of experiencing cultural diversity 
and appreciating differences. Although this is one voice who opposes homeschooling, the parent participants in this study report the importance of considering the ways in which they will expose their children to differing values.

Conversations with some of the mothers in the study indicate a commitment to provide opportunities for their adolescents to experience and appreciate cultural, socio-economic, and ideological diversity. The vast plethora of activities in which the participants' adolescent children were engaged (Appendix J) certainly provided opportunities for engagement with individuals and organizations representative of political, spiritual, socio-economic, racial, and other cultural differences. Immersion for seven or eight hours a day in an environment resplendent with these differences is not considered necessary by the mothers for their adolescents to value, appreciate, and understand such differences.

The adolescent children of the mothers in this study were all active in a homeschooling coop. All respondents said that their groups typically meet once a week during the school year. The format appears to vary from group to group. Some focus on specific academic areas utilizing the expertise of parents within the group to provide instruction and/or enrichment. Examples of subjects available through coop participation included computer coding, secondary literature, poetry and drama, various music classes, chemistry, wildlife biology, and human anatomy. Some mothers use the coop as a venue for semi-structured physical education classes and/or activities. One mother in the study said that their group chooses one academic and one physical education focus each semester. Some of the families in the study belonged to coops that were activity-oriented, going to special community events as a group; examples included musicals, state park programs, museums, historical sites, and government-related events. Koepke and Denissen's (2012) contend that, “a stable, structured social environment in which role models are provided is an important resource for identity formation" (p. 85). Gathercole (2007) emphasizes the importance of role models as well as peer interactions to 
healthy child and adolescent development. Homeschooling parents are usually quick to point out that trusted adults are more appropriate role models than adolescent peers, yet at the same time, they acknowledge the critical importance of peer relationships during the adolescent years. Homeschooling provides the opportunity for peer interaction, meaningful relationships with individuals of diverse backgrounds and ages, with supportive parenting. Erikson (1968) stated, "The adolescent looks most fervently for men and ideas to have faith in, which also means men and ideas in whose service it would seem worthwhile to prove oneself trustworthy" (p. 129). It can be postulated that homeschooling can facilitate identity formation through the provision of opportunities for exploration of interests and organizations to which one may eventually commit, and through the intentional support and active involvement of parents.

Mothers expressed the belief that they could much more effectively teach critical thinking skills to their children than could anyone else. Several studies (Gaither, 2008; Kunzman \& Gaither, 2013; Muntes, 2006; Ray, 2009; Van Galen, 1991) that examined parental motives for homeschooling found the position taken by parents who homeschool to be in diametric opposition to Reich's assertions. That is certainly true for the parent participants in this study. Although the stated motivation for homeschooling by many parents in the study was to pass on their values to their children, there was evidence that the parents were intentional in promoting the critical thinking skills necessary for personal evaluation of ideas and beliefs. Parents overwhelmingly voiced the desire for their children to learn and demonstrate appropriate values and social skills. However, they want to be the primary role models and teachers of that knowledge and skill set. Mothers voiced desires for: quality family time, less stress, fostering close family relationships, and opportunities to have more "life teaching moments." Prior research (Aurini \& Davis, 2005; Gaither, 2008; Kunzman, 2009) demonstrated the inculcation of values to be a leading motivation for parents to homeschool. 
From an Eriksonian view, it may be challenging to suggest that a home education based upon a religious/moral motivation alone would provide the encouragement for the exploration necessary to achieve identity. However, parents who cite religious/moral reasons for homeschooling are not fashioning their interactions with their adolescents solely on religious instruction. Rather, it is the integration of faith-based principles with academics that guides their instruction. Further research is definitely warranted to explore if there is any difference between the identity statuses of adolescents whose parents homeschool on the basis of religious/moral convictions and the identity statuses of adolescents whose parents' primary motivations are related to academic and/or environmental concerns. It appears that parents who are motivated by moral and/or religious reasons to homeschool their children are attempting to create and maintain the type of stable, secure environment that Erikson identified as foundational to the formation of identity.

\section{Homeschooling Methods and Adolescent Identity Formation}

Secure parent-child relationships provide an optimal foundation for the adolescent's quest for independence (Perosa, Perosa, \& Tam, 2002). Healthy bi-directional relationships have been identified by homeschooling parents as one of the primary benefits of homeschooling (Davis, 2005; Gaither, 2008; Gathercole, 2007; Griffith, 1998). The freedom to pursue individual interests is integral to the achievement of an individual identity (Erikson, 1968). The homeschool environment provides the flexibility necessary to address individual learning needs, according to the parents interviewed. For example, parents believe that the engagement and communication between parent and adolescent that occurs daily in the process of homeschooling is inherent in the individualization of instruction and integral to healthy identity formation.

Limitations. There were some limitations associated with this study. The first involved the use of purposive sampling. Secondly, the educational levels of parents were significantly 
high as compared to the homeschool population. Thirdly, there were no unschoolers in the study.

Sampling methodology. As previously noted, direct access to home schooling families is significantly limited for many reasons, thus a randomized sample could not be obtained. Social media was used as the vehicle for recruiting participants for the study, which in itself could be a limiting factor as it cannot be assured that all homeschooling families in Pennsylvania have direct internet access and/or are regular users of social media. It naturally follows in this case that convenience sampling could represent a significant over or under representation of homeschooling families.

Parent educational levels. The educational levels of parents who homeschool their children have been documented rather consistently since the 1980's (Murphy, 2012). The most recent data provides estimates for college completion of homeschooling parents to be $62.5 \%$ for mothers and $66.3 \%$ for fathers (Ray, 2010). In this study $92 \%$ of the mothers had completed a college degree, with two of those having acquired master's degrees. This is obviously unusually high and could significantly influence every aspect of the educational practice and procedures within the home and could certainly have affected the responses provided in this study. Further, it is reasonable to question if a correlation exists between the willingness to participate in research and parental education level. Based upon informal conversations with homeschooling parents, there is justifiable reason to speculate that parents with a college degree have a higher level of confidence in their ability to adequately address their adolescent's educational and psychosocial needs.

Unschooling. Self-descriptions of methodology demonstrated significant variance. (Appendix G) However, there were no motherss in the study who identified 'unschooling' as their methodology. It must be noted that 'methodology' would be considered inappropriate nomenclature by parents who follow 'unschooling' in their home. Rather, it would be viewed as 
a lifestyle. The absence of unschoolers in the study raises important questions: (1) Are those who follow no formal or semi-formal program less likely to participate in research? (2) Is there a difference in the quantity and/or quality of experiences available to unschoolers as compared to other homeschoolers? (3) Is there a difference in the educational levels of parents who follow unschooling as a practice? If so, is it significant to the opportunities for growth and learning as necessary for identity formation?

\section{Implications for Future Research}

The need for further study of the psychosocial outcomes related to homeschooling is definitely warranted. This study provided a glimpse into the motivations and methods of the parents who participated and gives a basis for the postulates which follow. However, generalization to the broader population of homeschooling families is not possible. Progress must be made in the processes and procedures of obtaining randomized samples of homeschooling families to provide empirical data that can yield generalizable results.

The analyses of parent responses elicited significant questions that could serve as the basis for further research: (1) How do homeschooled adolescents view their opportunities for self-expression and exploration? (2) Assuming an adequate sample size, how does the identity formation of homeschooled adolescents compare to a validation sample of adolescents? (3) Is there a correlation between the educational level of parents and the opportunities provided for adolescent exploration relevant to identity formation? (4) What type of differences are there in civic engagement of early adults who were homeschooled as compared to those who were traditionally educated? (5) All of the adolescent children of the mothers in this study were involved in homeschool coops. One could reasonably ask to what extent those experiences are benefitting them more than homeschooled adolescents who do not participate in coops. In other words, is there a difference in adolescent engagement and exploration of individual interests between those who are involved in coops and those who are not? 


\section{Summary}

The number of families who are homeschooling has burgeoned in the last 40 years. What began as a fringe movement of ideological progressives, soon included those from the religious right and to some degree homeschooling became associated with conservative philosophy. Demographics have shifted substantially; while most homeschooling families have historically been representative of middle income, white, politically conservative ideologies, the number of minorities, highly-educated, suburban, and politically-liberal families has been increasing consistently since the beginning of this century. One may never know with certainty whether homeschooling represents an "alternative to modernity or an expression of it" (Gaither, 2008, p. 225). The increasing interest, appeal, and investment in educating the next generation at home necessitates an understanding and examination of the process by society at large, and most definitely by those involved in and invested in the practice of education.

The commitment to provide a quality academic education, the desire to provide an optimal learning environment, and the hope to instill appropriate social mores and personal values were all clear themes articulated by the mothers in this study. There were numerous other subthemes that are worthy of future research and would certainly provide more insight into the possible benefits and/or disadvantages associated with homeschooling. This study has provided a basis for postulating that the process of homeschooling an adolescent may facilitate the formation of identity. The key elements necessary for the development of an individual identity, as defined by Erik Erikson (1959) and further developed and explained by Marcia (1966) are available in the home. The mothers in this study are providing opportunities for the exploration that is an integral component of identity formation. The intentional exposure to novel experiences that helps adolescents gain individual perspectives and develop personal beliefs and values, is frequently inherent in the process of home education. 
Mothers in this study articulated the desire to provide opportunities for their adolescents to explore their personal interests and ideas, and to develop their individual strengths as well as to support them in making independent choices. The mothers appeared to possess a strong belief that promoting individualism and teaching family values are not mutually-exclusive. Rather, parental modeling and articulation of values can be viewed as foundational in teaching an adolescent critical thinking skills necessary to formulate and defend his/her personal values and beliefs. Quite simply stated, there exists, within this sample of mothers who homeschool, an opportunity for quality bi-directional interactions, consistent parental engagement and support, and opportunities for adolescent exploration that is foundational to the formation of identity. 


\section{References}

Adams, G., Dyk, P., Bennion, L. (1990). Parent-adolescent relationships and identity formation. In B. K. Barber \& B. C. Rollins (Eds.), Parent-adolescent relationships (pp.1-16). Lanham, MD: University Press of America.

Adams, G., \& Gullotta, T. (1989). Adolescent life experience. Pacific Grove, CA: Brooks-Cole.

Adams, G., \& Marshall, S. (1996). A Developmental social psychology of identity: understanding the person in context. Journal of Adolescence, 19, 429-442.

Adams, G., Abrahams, K., \& Markstrom, C. (1987). Relations among identity development, selfconsciousness and self-focusing during middle and late adolescence. Developmental Psychology, 23, 292-297.

Allen, J., Hauser, S., Bell, K., \& O'Connor, T. (1994). Longitudinal assessment of autonomy and relatedness in adolescent-family interactions as predictors of adolescent ego development and self-esteem. Child Development, 65, 179-194.

Allen, J., McElhaney, K., Land, D., Kuperminc, G., Moore, C., O’Beirne-Kelly, H, \& Kilmer, S. (2003). A secure base in adolescence: Markers of attachment security in the motheradolescent relationship. Child Development. 4, 292-307.

Allen, J., Moore, C., Kuperminc, G., \& Bell, K. (1998). Attachment and adolescent psychosocial functioning. Child Development 69(5), 1406-1419.

Apter, Terri. (1990). Altered loves: Mothers and daughters during adolescence. New York, NY: Random House.

Armsden, G., \& Greenberg, M. (1987). The Inventory of parent and peer attachment: Individual differences and their relationship to psychological well-being in adolescence. Journal of Youth and Adolescence. 16, 427-453.

Aurini, J., \& Davies, S. (2005). Choice without markets: Homeschooling in the context of private education. British Journal of Sociology of Education, 26, 461-474. 
Bandura, A. (1964). The stormy decade: Fact or fiction? Psychology in the Schools, 1,224-231.

Baruch, B. (1947). Retrieved from https://quoteinvestigator.com/2012/12/04/those-who-mind/

Bauer, S., \& Wise, J. (2009). The well-trained mind: A guide to classical education at home. New York, NY: Norton.

Bauman, K. (2002). Homeschooling in the United States: Trends and characteristics. Education Policy Analysis Archives, 10(26), 1-21.

Bauman, Z. (2000). Liquid Modernity. Malden, MA: Polity Press.

Belfield, C. (2004). Homeschooling in the U.S. (Research paper 88). National Center for the Study of Privatization in Education, Teacher College Columbia University. Retrieved from http://ncspe.org/publications_files/0P132.pdf.

Bell, G., \& Bell, D. (2009). Effects of family connection and family individuation. Attachment and Human Development, 11(5), 471-490.

Berzonsky, M. (2004). Identity style, parental authority, and identity commitment. Journal of Youth and Adolescence, 33(3), 213-220.

Beyers, W., \& Goossens, L. (2008). Dynamics of perceived parenting and identity formation in late adolescence. Journal of Adolescence, 31, 165-184.

Blos, P. (1962). On Adolescence: A psychoanalytic interpretation. New York, NY: Macmillan Publishing.

Blos, P. (1979). The adolescent passage: Developmental issues. New York, NY. International Universities Press.

Bosma, H., \& Kunnen, E. (2001). Determinants and mechanisms in ego identity development: A review and synthesis. Developmental Review, 21, 39-66.

Bowen, M. (1978). Family therapy in clinical practice. New York, NY: Aronson.

Bowlby, J. (1969). Attachment and loss. New York, NY: Basic Books. 
Bowlby, J. (1988). A secure base: Parent-child attachment and healthy human development. New York, NY: Basic Books.

Braun, V., \& Clarke, V. (2006). Using thematic analysis in psychology. Qualitative Research in Psychology. 3, 77-101.

Bronfenbrenner, U. (1979). The Ecology of human development: Experiments by nature and design. Boston, MA: The President and fellows of Harvard College.

Chang, C. (2015). The effects of friendship and antipathy networks on adolescent attitude similarity. International Journal of Adolescence and Youth, 20(4), 407-428.

Cizek, G. (1993). The mismeasure of home schooling effectiveness (a commentary). Home School Researcher, 9(3), 1-4.

Cochran, C. (1999). A radical ideology for home education: The journey of John Holt from school critic to home school. Home School Research Journal, 13(3), 1-10.

Davis, M. (2005). So, why do you homeschool? Answering questions people ask about home education, 101-102. Longwood, FL: Xulon Press.

Dekovic, M., \& Meeus, W. (1997). Peer relations in adolescence: effects of parenting and adolescents' self-concepts. Journal of Adolescence 20(2), 163-176.

Doctors, S. (2013). Attachment-individuation: Clinical notes toward a reconsideration of adolescent turmoil. In A. Esman (Ed.), Annals of the American Society for Adolescent Psychiatry (3-16). Hillsdale, NJ: The Analytic Press.

Eccles, J., Midgley, C., Wigfield, A., Buchanan, C., Reuman, D., Flanagan, C., \& MacIver, D. (1993). Development during adolescence: The impact of stage-environment fit on adolescents' experiences in schools and families. American Psychologist, 48, 90-101.

Elkind, D. (1988). The Hurried child. New York, NY: Addison-Wesley.

Erikson, E. (1959). Identity and the life cycle. New York, NY: Norton. 
Erikson, E. (Ed.). (1963). Youth: Change and challenge. New York, NY: Basic Books.

Erikson, E., (1968). Identity, youth and crisis. New York: Norton.

Gaither, M. (2008). Homeschool: An American history. New York, NY: Palgrave Macmillan.

Gaither, M. (2010, May 3). Homeschooling research notes: Discussing research about homeschooling history, policy, and practice. New Ray study of homeschooler demographics and achievement. Message posted to https://gaither.wordpress.com/2010/05/03/new-ray-study-of-homeschoolerdemographics-and-achiemement/\#more-1487.

Galambos, N., Barker, E., \& Almeida, D. (2003). Parents do matter: Trajectories of change in externalizing and internalizing problems in early adolescence. Child Development. 74, $578-94$.

Gathercole, R. (2007). The well-adjusted child, the social benefits of homeschooling. Denver, CO: Mapletree Publishing.

Green, C., \& Hoover-Dempsy, K. (2007). Why do parents homeschool? A systematic examination of parental involvement. Education and Urban Society. 39(2), 264-285.

Greenberg, M., Siegel, J., \& Leitch, C. (1983). The nature and importance of attachment relationships to parents and peers during adolescence. Journal of youth and adolescence. $12(5), 373-386$.

Griffith, M. (1998). The unschooling handbook. New York, NY: Random House.

Grusec, J., \& Davidov, M. (2010). Integrating different perspectives on socialization theory and research: A domain specific approach. Child Development, 81, 687-709.

Hala, S. (1997). The development of social cognition. East Sussex, UK, Psychology Press Ltd. Harris, J. (2000). Socialization, personality development, and the child's environments. Developmental Psychology, 36(6), 711-723. 
Hay, I., \& Ashman, A. (2003). The development of adolescents' emotional stability and general self-concept: The interplay of parents, peers, and gender. International Journal of Disability, Development and Education. 50(1), 77-91.

Hershberg, R., Johnson, S., DeSouza, L., Hunter, C., \& Zaff, J. (2015). Promoting contribution among youth: Implications from positive youth development research for youth development programs. Lessons from the 4-H study. In E. P. Bowers, G. J. Geldhof, S. K. Johnson, L. J. Hilliard, R. M. Hershberg, J. V. Lerner, \& R. M. Lerner, (Eds.), Positive youth development. New York, NY: Springer.

Hogan, R., \& Roberts, B. (2004). A socioanalytic model of maturity. Journal of Career Assessment, 12, 207-217.

Holmbeck, G., Paikoff, R., \& Brooks-Gunn, J. (1995). Parenting adolescents. In M. H. Bornstein (Ed.), Handbook of parenting (pp. 91-118). Hillsdale, NJ: Erlbaum.

Homeschool Alumni Reaching Out (HARO, 2015). Announcing the results from HARO's 2014 survey of homeschool alumni. International Center for Home Education Research Reviews. Retrieved from: https://hareachingout.files.wordpress.com/2014/12/survey1.pdf

Holt, J. (1964). How children fail: Classics in child development. New York, NY: Pitman Press. Isenberg, E. (2007). What have we learned about homeschooling? Peabody Journal of Education, 82(2-3), 387-409.

Josselson, R. (1991). Finding herself: Pathways to identity development in women. San Francisco, CA: Jossey-Bass.

Koepke, S., \& Denissen, J., (2012). Dynamics of identity development and separationindividuation in parent-child relationships during adolescence and emerging adulthood a conceptual integration. Developmental Review, 32, 67-88.

Kroger, J. (2004). Identity in adolescence: The balance between self and other ( $3^{\text {rd }}$ ed.). New York, NY: Routledge. 
Kroger, J. (2007). Identity development: Adolescence through adulthood (2 $2^{\text {nd }}$ ed.). Thousand Oaks, CA: Sage Publications.

Kuhn, D. (2009). The Importance of learning about knowing: Creating a foundation for development of intellectual values. Child Development Perspectives, 3, 112-117.

Kunzman, R. (2009). Write these laws on your children: Inside the world of conservative Christian homeschooling. Boston, MA: Beacon Press.

Kunzman, R. (2012). Education, schooling, and children's rights: The complexity of homeschooling. Educational Theory, 62(1), 75-89.

Kunzman, R., \& Gaither, M. (2013). Homeschooling: A comprehensive survey of the research. Other Education: The Journal of Educational Alternatives, 2(1), 4-59.

Leary, M. (2005). Sociometer theory and the pursuit of relational value: Getting to the root of self-esteem. In R. M. Lerner, \& L. Steinberg (Eds.), European Review of Social Psychology, Handbook of adolescent psychology, 16, 75-111. Hoboken, NJ: Wiley.

Leigh, G., \& Peterson, G. (1986). Adolescents in families. Cincinnati, OH: Southwestern Publishing.

Lerner, R., Jacobs, F., \& Wertlieb, D. (Eds.). (2003). Handbook of applied developmental science: Promoting positive child, adolescent, and family development through research, policies, and programs. Thousand Oaks, CA: Sage Publications.

Lezin, N., Rolleri, L., Bean, S., \& Taylor, J. (2004). Parent-child connectedness: Implications for research, interventions, and positive impacts on adolescent health. Scotts Valley, CA: ETR Associates.

Lines, P. (2000). When home schoolers go to school: A partnership between families and schools. Peabody Journal of Education, 75(1\&2), 159-186. 
Maccoby, E. (2007). Historical overview of socialization and theory. In J. E. Grusec \& P. D.

Hastings, Handbook of socialization: Theory and practice. pp. 13-41. London, England: Guilford Press.

MacDonald, K. (1987). Biological and psychosocial interactions in early adolescence: A sociobiological perspective. In R. Lerner \& T. Foch (Eds.), Biological and psychosocial interactions in early adolescence: A life-span perspective. Hillsdale, NJ: Erlbaum.

Marcia, J. (1966). Development and validation of ego identity status. Journal of Personality and Social Psychology, 3, 551-558.

Marcia, J. (1980). Identity in Adolescence. In J. Adelson (Ed.), Handbook of Adolescent Psychology, pp. 159-187. New York, NY: Wiley.

Marcia J. (1993). The ego identity status approach to ego identity. In J.E. Marcia, A. S. Waterman, D. R. Matteson, I. I. Archer, \& J. L. Orlofsky (Eds.), Ego identity: A handbook for psychological research (pp. 3-21). New York, NY: Springer-Verlag.

Marlow, S. (1994). Educating children at home: Implications for assessment and accountability. Education and Urban Society, 26, 438-460;

Markstrom-Adams, C. Ascione, F., Braegger, D., \& Adams, G. (1993). Promotion of egoidentity development: Can short-term intervention facilitate growth? Journal of Adolescence. 16, 217-224.

Markstrom, C., \& Marshall, S. (2007). The psychosocial inventory of ego strengths: Examination of theory and psychometric properties. Journal of Adolescence, 30, 63-79.

Markstrom, C. Berman, R., Sabino, V., \& Turner, B. (1988). The ego virtue of fidelity as a psychosocial rite of passage in the transition from adolescence to adulthood. Child \& Youth Care Forum, 27(5), 337-354.

Mayberry, M., Knowles, G., Ray, B., \& Marlow, S. (1995). Home schooling: Parents as educators. Newbury Park, CA: Corwin Press. 
McMahan, I. (2009). Adolescence. Hoboken, NJ: Pearson Publishers.

Moore, R. (1972). The Dangers of early schooling. Harper's Magazine. 245, 1466.

Moretti, M., \& Peled, M. (2004). Adolescent-parent attachment: Bonds that support healthy development. Pediatric Child Health, 9(8), 551-555.

Moshman, D. (1999). Adolescent psychological development: Rationality, morality, and identity. Mahweh, NJ: Lawrence Erlbaum Associates Publishers.

Muntes, G. (2006). Do parental reasons to homeschool vary by grade? Evidence from the National Household Educational Survey. Homeschool Researcher, 16(4), 11-17.

Murphy, J. (2012). Homeschooling in America: Capturing and assessing the movement. New York, NY: Skyhorse Publishing.

Murphy, J. (2013). Explaining the changes in homeschooling. Home School Research Journal, 29(1), 1-13.

Muuss, R. (1988). Theories of adolescence. ( $5^{\text {th }}$ ed.). New York, NY: Random House.

National Center for Education Statistics (2015). Digest of Education Statistics. Retrieved from https://nces.ed.gov/programs/digest/d13/tables/dt13_206.10.asp?current=ye

Nauta, N., \& Kahn, J. (2007). Identity status, consistency and differentiation of interest and career decision and self-efficacy. Journal of Career Assessment, 15(1).

Neufeld, G., \& Mate, G. (2014). Hold on to your kids: Why parents need to matter more than peers. New York, NY: Ballantine Books.

Parsons, R., Nalbone, D., Killmer, J., \& Wetchler, J. (2007). Identity development, differentiation, personal authority, and degree of religiosity as predictors of interfaith marital satisfaction. American Journal of Family Therapy. 35(4), 343-361.

Paterson, J., Pryor, J., \& Fields, J. (1995). Adolescent attachment to parents and friends in relation to aspects of self-esteem. Journal of Adolescence, 24, 365-376. 
Perosa, L., Perosa, S., \& Tam, H. (2002). Intergenerational systems theory and identity development in young adult women. Journal of Adolescence Research, 17, 235-259.

Qualtrics Survey Software. (2017). Informer Technologies. Retrieved from https://www.qualtrics.com/research-core.

Ray, B. (2004). Homeschoolers on to college: What the research shows us. Journal of College Admissions, 185, 5-11.

Ray, B. (2005). A homeschool research story. In B. S. Cooper (Ed.), Home schooling in full view. (pp 1-19). Greenwich, CT: Information Age.

Ray, B. (2009). Home education, reason and research. Salem, OR: NHERI Publications.

Ray, B. (2010). Academic achievement and demographic traits of homeschool students: A nationwide study. Academic Leadership: The Online Journal, 8(1), 1-32. Retrieved from: http://www.academicleadership.org/article/Academic_Academic_and_Demographic_Trai ts_of_Homeschool_Students_A_Nationwide_Study/homeschool.

Reich, R. (2005). Why homeschooling should be regulated. In B.S. Cooper (Ed.), Home schooling in full view. (pp. 109-120). Greenwich, CN: Information Age.

Reitz, A., Zimmermann, J., Hutteman, R., Specht, J., \& Neyer, F., (2014). How peers make a difference: The role of peer groups and peer relationships in personality development. European Journal of Personality. 28, 279-298.

Resnick, M., Bearman, P., Blum, R., Bauman, K., Harris, K., Jones, J., Tabor, J., Beuhring, T., Sieving, R., Shew, M, Ireland, M., Bearinger, L., \& Udry, J. (1997). Protecting adolescents from harm: Findings from the national longitudinal study on adolescent health. Journal of the American Medical Association, 278(10), 823-832.

Rudner, L. (1999). Scholastic achievement and demographic characteristics of home school students in 1998. Educational Policy Analysis Archives, 7(8). Retrieved from: http://epaa.asu.edu/ojs/article/viewFile/543/666. 
Schmidt, K., Dayanim, S., \& Matthias, S. (2008). Personal homepage construction as an expression of social development. Developmental Psychology, 44(2), 496-506.

Smith, C., \& Sikkink, D. (1999). Is private schooling privatizing? First Things: A Monthly Journal of Religion and Public Life, 16-20.

Smits, I., Soenens, B., Luyckx, K., Druiez, B., Brozonsky, M., \& Goosens, L. (2008). Perceived parenting dimensions and identity styles: Exploring the socialization of adolescents' processing of identity-relevant information. Journal of Adolescence, 31, 151-164.

Sowell, E., Thompson, P., Holmes, C., Batth, R., Jemigan, T., \& Toga, A. (1999). Neuroimage. $9(6), 587-597$.

Stevens, M. (2001). Kingdom of children: Culture and controversy in the homeschooling movement. Princeton, NJ: Princeton University Press.

Strauss, A., \& Corbin, J (1990). Basics of qualitative research: Grounded theory procedures and techniques. Newbury Park, CA: Sage.

Steinberg, L. (2008). Adolescence. (E. Barrosse, Ed.). ( $8^{\text {th }}$ ed.). New York, NY: McGraw Hill Higher Education.

Sukarieh, M., \&Tannock, S. (2011). Positive imperative. Journal of Youth Studies, 14(6), 675691.

Swann, W. (1987). Identity negotiation: Where two roads meet. Journal of Personality and Social Psychology, 53, 1038-1051.

Taylor, V. (2005). Behind the trend: Increases in homeschooling among African American families. In B.S. Cooper (Ed.), Home schooling in full view. Greenwich, CT: Information Age, 121-133.

United States Census Bureau (2014). Retrieved from https://www.census.gov/topics/families.html 
United States Department of Education, (2013). National Center for Education Statistics.

Retrieved from https://nces.ed.gov/pubs2013/2013028/tables/table_07.asp.

Van Galen, J. (1991). Ideologues and pedagogues: Parents who teach their children at home. In J. Van Galen \& M. Pitman (Eds.), Homeschooling: Political, historical, and pedagogical perspectives (pp. 63-76). Norwood, NJ: Ablex.

Vigilant, L., Trefethren, L., \& Anderson, T. (2013). You can’t rely on somebody else to teach them something they don't believe: Impressions of legitimation crisis and socialization control in the narratives of Christian homeschooling fathers. Humanity and Society, 37(3), p.201-224.

Wartes, J. (1990). Recent results from the Washington homeschool research project. Home School Researcher, 6(4), 1-7.

Wessling, S. (2013). Authoritative homeschooling. from http://blog.sukiwessling.com/2013/05/authoritative-homeschooling/

White, S., Moore, M., \& Squires, J. (2009). Examination of previously home-schooled college students with the big five model of personality. Home School Researcher, 25(1), 1-7.

Yablonska, T. (2013). Family factors of person's identity development during adolescence and early adulthood. Social Welfare Interdisciplinary Approach. 3(2), 30-40.

Yuracko, K. (2008). Education off the grid: Constitutional constraints on home schooling. California Law Review, 96, 123-184. 


\section{Appendix A: Marcia's Identity Statuses Defined}

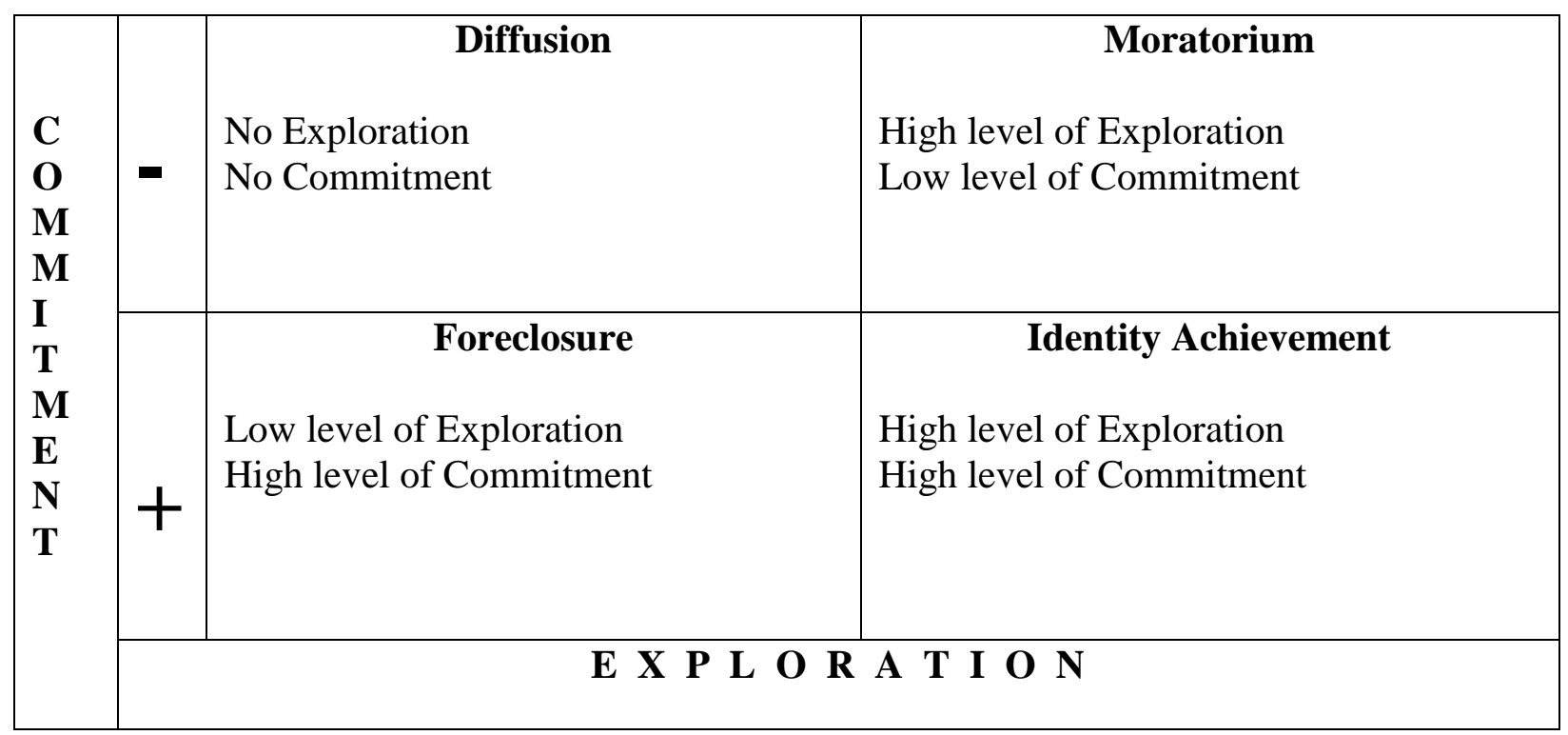

\section{Explained}

\begin{tabular}{|c|c|c|c|}
\hline \multirow{3}{*}{$\begin{array}{l}\mathbf{C} \\
\mathbf{O} \\
\mathbf{M} \\
\mathbf{M} \\
\mathbf{I} \\
\mathbf{T} \\
\mathbf{M} \\
\mathbf{E} \\
\mathbf{N} \\
\mathbf{T}\end{array}$} & ש & $\begin{array}{l}\text { Diffusion } \\
\text { Characterized by a lack of purpose, } \\
\text { direction, and/or life goals. There is an } \\
\text { absence of exploration and } \\
\text { commitment and frequently a lack of } \\
\text { awareness. }\end{array}$ & $\begin{array}{l}\text { Moratorium } \\
\text { Characterized by an awareness of "not } \\
\text { knowing" accompanied by a desire to } \\
\text { find direction. }\end{array}$ \\
\hline & + & $\begin{array}{l}\text { Foreclosure } \\
\text { Characterized by commitments to } \\
\text { beliefs (generally those held by } \\
\text { significant others) without exploration } \\
\text { of options. Beliefs are strongly held } \\
\text { but not generally questioned. }\end{array}$ & $\begin{array}{l}\text { Identity Achievement } \\
\text { Characterized by self-made commitments } \\
\text { to particular ideologies, institutions, and } \\
\text { choice of profession. Occurs as a result } \\
\text { of exploration and the resultant crisis of } \\
\text { identity. }\end{array}$ \\
\hline & & 21 & TIO N \\
\hline
\end{tabular}

(Marcia, 1980) 
IDENTITY FORMATION AND HOME SCHOOLING

\section{Appendix B: Letter of Invitation to Parents posted on Listservs and Social Media}

\section{Re: Homeschooling Adolescents \\ Dear Parent,}

As you are likely aware, there have been several research studies about the academic achievement of children who are homeschooled. Such studies generally suggest very positive outcomes. However, there has been very little research about the process of becoming oneself (known as identity formation) for adolescents who are homeschooled. As a former homeschooling parent and teacher, I have a passion for understanding how children learn and am conducting a study to examine the role of homeschooling in the adolescent's formation of identity. I hope that you will participate.

This study is totally voluntary. As the surveys and questionnaires are completed online, the answers are anonymous. It will take about 20 minutes for both you and your adolescent to complete. You are welcome to ask any questions you have about the study by contacting me at homeschool.research.pmcqueen@gmail.com

I sincerely appreciate your participation. 


\section{Appendix C: Letter to Homeschool Support Group Coordinators}

Dear Coordinator,

Can you believe it's nearly that time of year when home school parents attempt to put into words and document in some way the learning that has occurred during the last several months? As a former home school mom, I remember what a daunting task it was to substantiate some of the growth and learning that I had seen as a parent. The measures of academic progress were there but it sometimes seemed to evade me. The social/emotional growth can be even more of a challenge to document, yet it is such a very real part of the learning experience.

I have always been interested in the way children learn thus when my own children were grown, and after teaching in public and private school for several years, I returned to college to pursue a doctoral degree in education. I am currently completing my dissertation on "Identity Development in Adolescents who are Homeschooled." My study involves surveys taken online by parents and their adolescent children. It is totally anonymous.

I must secure the permission of Homeschool Support Group Coordinators in order to solicit participation from members, before I can begin the study. Quite simply, I am asking for your permission to post a description of the study on your website or listserv. If your group does not have a website or listserv, I am asking that you would forward the description of the study via email to your group members. Your permission to allow me to post a study description on your website/listserv or your agreement to forward the study description to group members does not obligate you or any of your group members in any way.

I hope to demonstrate the benefit of homeschooling to the development of an individual identity. I believe the results of the study will provide meaningful information for homeschool parents and hope to have participation from families throughout the state of Pennsylvania.

You can grant permission for me to solicit participants from your group, as outlined above, by copying and pasting the following sentence in a reply to this email.

I grant my permission to Peggy McQueen to post a description of her research study on my Homeschool Support Group's website/listserv in order to solicit participants from the group and/or I am willing to forward a description of the study via email to group members.

Thank you in advance for your cooperation. It is greatly appreciated.

Sincerely, Peggy McQueen 


\title{
Appendix D: Introduction and Instructions
}

\author{
Welcome to the research study on: \\ Identity Formation in Adolescents Who Are Homeschooled
}

\section{Introduction:}

I have long been interested in Homeschooling, both as a homeschool parent and as a formal educator. I well remember the many "What if _ " questions from well-meaning family and friends and some from others, perhaps not quite as well-meaning. As I am sure you have experienced, the blank could be filled in with almost anything from strictly academic to social to emotional well-being. The focus of this study is on the adolescent development of an individual identity. I want to examine the potential benefit of homeschooling in the process of adolescent identity formation.

\section{Instructions for Participation in the Study:}

1. Complete the Parent Information Form. This information will be used for completion of the data analysis. For example, it will be helpful to know how many years you have been homeschooling and how many children you currently homeschool.

2. After completing the Parent Information Form, please next answer the five open-ended questions on the Parental Response Form. This form provides the opportunity for you to express in your own words your personal thoughts regarding methodology and reasons for homeschooling.

3. Next, complete the Parental Motivation for Homeschooling Form. This form categorizes the post commonly parent-cited reasons for homeschooling.

4. Complete the Homeschooling Methodology Form. This information will help provide a picture of the most common methods that are employed in homeschooling.

5. After you complete the survey and click submit, the results will be sent to me. 


\section{Appendix E: Parental Information - Demographics}

GENERAL INFORMATION (this form will be a file upload question attached to the adolescent EOM-EIS)

Please provide the following information for analytical purposes.

1. What is your child's gender? Male Female

2. What is your child's age?

3. What is your child's birth order? (e.g. $1^{\text {st }}$ child, $2^{\text {nd }}$ child, etc.)

4. What is your child's racial/ethnic background?

5. Does your child require any specialized instruction as a result of a learning challenge related to any of the following: visual (not correctable by lenses), hearing, orthopedic, physical, emotional, mental health, mental impairment, learning disability, or other? If so, please specify.

6. Who is your child's primary instructor? (If instruction is in a self-paced or online format, please so note and identify the person responsible for monitoring progress).

7. What is the educational level of the person listed above?

8. If there is another parent residing in the home, what is his/her educational level?

9. How many years has this child been homeschooled? If this is the first year, count it as one year.

10. Does your child participate in any extracurricular activities through your school district? If so, please specify the activity and the frequency of involvement.

11. Does your child participate in any extracurricular activities through a homeschool network, community organization, and/or church-sponsored venue? If so, please specify the activity and the frequency of involvement. 


\section{Appendix F: Parental Response}

\section{Parent Response - Identity Formation in Homeschooled Adolescents}

1. Tell me about your motivation for homeschooling your adolescent.

2. Why do you continue to homeschool?

3. Please describe the degree of structure in your homeschooling experience.

4. How are your motivation for homeschooling and the structure (or methods) you use related?

5. In what ways do you believe that the homeschooling experience influences and/or impacts your child's maturation as a unique individual? 


\section{Appendix G: Parental Motivation}

\section{MOTIVATION OR REASON FOR HOMESCHOOLING}

There are many different reasons that parents choose to homeschool their children. Please check all the reasons that apply for this child and rank order the top three reasons (In other words, you may check as many as apply, whether that is only one or all fifteen. However, of those that you check, please rank the top three reasons by placing a 1, 2, or 3 beside the checkmark).

1. ___ Accomplish more academically than in conventional schools.

2. Child has special needs that you feel the school can't or won't meet.

3. __ Concern about the school environment, such as safety, drugs, or negative peer pressure.

4. T_ To develop stronger family relationships between children and parents and among siblings.

5. Dissatisfied with the academic instruction at other schools.

6. To transmit values, beliefs, and worldview to the child.

7. ___ Provide a more international perspective or worldview.

8. ___ Provide religious or moral instruction.

9. ___ Provide guided and reasoned social interactions with youthful peers and adults.

10. ___ Provide safety from teasing, ostracizing, and/or bullying.

11. Too much time is wasted on non-essentials in the school system, resulting in substandard instruction.

12. To individualize our child's education.

13. To use pedagogical (teaching) approaches other than those typical in traditional schools.

14. Concern about the possibility of violence in the schools.

15. __ To use curricular materials that supports a worldview consistent with our values. 


\section{Appendix H: Methodology}

\section{HOMESCHOOLING METHODOLOGY}

Next, please identify the primary method you use in homeschooling your adolescent. With an understanding that every family is unique, as is every child within any given family, thus application of any particular methodology may not necessarily be application of that methodology in its purest form. Following are descriptors of some of the most common approaches to homeschooling. Please mark only the one that most closely represents the approach you use.

7. Classical Education - An approach also known as the Socratic Method.

Learning opportunities are built around the student's level of cognitive development.

Lessons tend to be highly structured, yet there is room for flexibility, based on student need.

8. Eclectic Education - An approach that employs a variety of curricula, ideas, and methodology, depending upon the subject and/or the student need. There may be a combination of parent-led instruction, on-line learning, and video.

9. “Charlotte Mason" - An approach which generally uses short lessons with an emphasis on focused attention and excellence of execution. Variation is built into the daily schedule. Knowledge is demonstrated from narration and discussion rather than test-taking.

10. Integrative Eclectic Education - An approach that integrates any of the first three approaches. Cognitive development and student interest are considered. Unit-type studies are often employed that focus on a topic which allows for cross-curricular 
integration. There is a high degree of structure in some areas and a lesser degree in others.

11.___ Unschooling Education - Unschooling is perhaps the most challenging methodology to describe because the focus is on the child's innate learning abilities and interests. To a large degree, it is based upon John Holt's teaching that "living is learning and learning is living." There is no structured curriculum.

12. Virtual (cyber) Education. An approach wherein all subject matter is delivered online. Students are enrolled through their local public school.

\section{HOMESCHOOLING - DEGREE OF STRUCTURE}

The "degree of structure" in the practice of home education varies greatly. It ranges from a very unstructured learning approach to the use of a preplanned, structured, and highly prescribed curriculum. The main method used for this child during this school year is:

1 Very Unstructured

2 Mostly Unstructured

3 Somewhat Unstructured, with structure as needed

4 Unstructured in some areas, somewhat structured in others

5 Structured in most areas, somewhat unstructured in others

6 Generally Structured

7 Very Structured

Comments regarding degree of structure: 


\section{Appendix I : Type of Homeschool Curriculum \\ TYPE OF HOMESCHOOLING - CURRICULUM}

Curriculum options have multiplied as homeschooling as grown. Please identify the curricular method that most closely describes what is used with the child in this study.

1. Packaged curricular materials. The curriculum includes everything necessary for instructional planning, teaching, and evaluation, for which the parent is responsible. Curriculum for each subject area may be purchased from different publishers or may be purchased as an entire program from one publisher.

2. Mixed curricular format. The curriculum represents an array of instructional programming, dependent upon student age, educational need, and parent preparedness. There may be a combination of commercially-available curricula, video learning, on-line learning, parent-created learning units, and student-generated topics of special interest.

3. Self-paced texts and workbooks. Student assume the responsibility for their own learning. Students (with or without parent's guidance) are encouraged to begin each day by establishing goals and noting the concepts to be learned. While it is common for self-paced programs to encourage goal setting by the student to varying degrees, it is possible for the student (and/or parent) eliminate that step and simply record what the student completes. While not all-inclusive, the following are examples of this methodological approach: (a) Paradigm Accelerated Learning (PAC), (b) Accelerated Christian Education (ACE), and Alpha Omega's LIFEPAC program. Upon completion of each PACE, students take a self-test. Parents serve as monitors. This type of curriculum written from a Christian worldview includes a daily Bible verse with a corresponding character trait. 
4. Self-paced computer-based programs. As in the self-paced texts and workbooks, the students assume responsibility for their learning, with the difference being the presentation format. Goal-setting is encouraged although not mandated. Two examples include: (a) Alpha Omega's Switched on Schoolhouse, which uses a physical CD-ROM to run the program and (b) Monarch, which is an internet-based program.

5. Virtual Charter School (also known as eSchool at home). The curriculum is provided online by the State Department of Education through the local school district. Parents have access to a structured, comprehensive lesson plan every day. Students can work at their own pace (to some degree) and parents are provided with the tools to facilitate progress. State-certified teachers are available to answer questions and assist with progress. Students may join their peers in public school for participation in extracurricular programs.

6. Umbrella Program of Distance Learning. Private schools, Christian schools, and Home-based education networks serve as the "provider" of curriculum that may employ a self-paced approach (which may be similar to and/or include elements of selfpaced programming). In some cases, the provider is responsible for monitoring and evaluating progress. In other situations, the parent assumes responsibility for some, if not all, instruction, with the provider being responsible for assessment of progress.

7. Unschooling Education. There is not a particular curriculum. In fact, many unschoolers say that a curriculum may interfere with learning and view "the world as the curriculum." Parents serve as facilitators encouraging children to explore their areas of interest. 
Appendix K : Adolescent Activities as Identified by Parent Participants

\begin{tabular}{|c|c|c|}
\hline Categories & Specific Activities & $\begin{array}{l}\text { Related, but not } \\
\text { specified activities }\end{array}$ \\
\hline Sports & $\begin{array}{l}\text { Competitive Fencing (1), Soccer (1), Horseback riding } \\
\text { (1), Skating (1), Volleyball team (2), Kung Fu (1), } \\
\text { Gymnastics (1), Weightlifting (1), Cross Country (1), } \\
\text { Track \& Field (1), Swimming (1), Baseball (1), } \\
\text { Basketball team (1), }\end{array}$ & $\begin{array}{l}\text { Sports }(1), \text { Weekly } \\
\text { gym class }(1)\end{array}$ \\
\hline Natural Sciences & $\begin{array}{l}\text { 4H (2), Nature class (1), Enrichment Science class (1), } \\
* \text { Zoo volunteer }(1), * \text { Equine facility volunteer }(1)\end{array}$ & \\
\hline $\begin{array}{l}\text { Civic/ } \\
\text { Volunteering }\end{array}$ & $\begin{array}{l}\text { *Zoo volunteer, *Equine facility volunteer, Boy Scouts } \\
\text { (6), Library volunteer (1), Hospital volunteer (1), } \\
\text { Mission's trips (2), }\end{array}$ & Volunteer work (2), \\
\hline Religious & $\begin{array}{l}\text { Church youth group (6), Youth quiz bowl (1), Assists } \\
\text { with Bible study (1), }\end{array}$ & $\begin{array}{l}\text { Regular church } \\
\text { activities (2), }\end{array}$ \\
\hline $\begin{array}{l}\text { Arts/Arts \& } \\
\text { Crafts }\end{array}$ & $\begin{array}{l}\text { Violin (1), Dance (1), Guitar (1), Piano (3), Choral, } \\
\text { Gavel club, Woodcarving (1), Voice, Orchestra (1) }\end{array}$ & $\begin{array}{l}\text { Drama }(2), \text { Band, } \\
\text { Guitar, Music, }\end{array}$ \\
\hline Miscellaneous & $\begin{array}{l}\text { Weekly homeschool coop (26), History club (1), } \\
\text { Community game nights (1), Enrichment group (2), }\end{array}$ & $\begin{array}{l}\text { Hobby class (1), } \\
\text { Clubs (1), }\end{array}$ \\
\hline
\end{tabular}

Notes:

- The numerals in parentheses indicate the number of respondents for the activity.

- Activities preceded by an asterisk are dually listed.

- Underlined activities are those with which participation is through the adolescent's local school district. 